\title{
Emitter Orientation as a Key Parameter in Organic Light-Emitting Diodes
}

\author{
Tobias D. Schmidt, ${ }^{1}$ Thomas Lampe, ${ }^{1}$ Daniel Sylvinson M. R., ${ }^{2}$ Peter I. Djurovich, ${ }^{2}$ \\ Mark E. Thompson, ${ }^{2}$ and Wolfgang Brütting ${ }^{1, *}$ \\ ${ }^{1}$ Institute of Physics, University of Augsburg, 86135 Augsburg, Germany \\ ${ }^{2}$ Department of Chemistry, University of Southern California, Los Angeles, California 90089, USA \\ (Received 11 May 2017; revised manuscript received 7 August 2017; published 20 September 2017)

\begin{abstract}
The distinct preferential alignment, i.e., horizontal orientation with respect to the substrate plane, of the optical transition dipole moment vectors (TDMVs) of organic dye molecules is of paramount importance for extracting the internally generated power of organic light-emitting diodes (OLEDs) to the outside world. This feature is one of the most promising approaches for the enhancement of the electrical efficacy in stateof-the-art OLEDs, as their internal quantum efficiencies are already close to the ultimate limit. If one can achieve complete horizontal orientation of the TDMVs, it is possible to increase the efficiency by at least $50 \%$ because alignment strongly influences the power dissipation into the different optical modes present in such a thin-film device. Thus, this feature of organic light-emitting molecules can lead to advanced performance for future applications. Therefore, we present here a review of recent achievements, ongoing research, and future tasks in this particular area of organic electronics.
\end{abstract}

DOI: 10.1103/PhysRevApplied.8.037001

\section{INTRODUCTION}

Organic light-emitting diodes (OLEDs) have gained considerable attention in the applied physics community over the last three decades. It was possible to continuously increase their internal efficiency from only a few percent in the early fluorescent heterojunction thin-film devices [1] until the ultimate limit of $100 \%$ came within reach in the early 2000 s by using phosphorescent-emitting materials [2-5]. This was the starting point for commercialization of devices based on organic LEDs as they exhibit numerous advantages like ultrathin appearance, light weight, flexibility, arbitrary shape, and even transparency [6]. In the meantime, OLEDs are an inherent part of daily life as they are implemented, e.g., in smart phone displays, and, more recently, also as television screens. In general lighting, they have also outperformed fluorescent tube efficiency [7]; however, the price per lumen is still too high to compete with inorganic white LEDs. Additionally, their performance in terms of the external quantum efficiency (EQE), i.e., the number of emitted photons per injected carriers, is still far below the theoretical limit, and the electrical long-term stability lags behind in competition with their inorganic counterparts. While the durability of these devices holds challenges for advanced chemistry, improvement of the EQE is feasible by physical mechanisms.

\section{BACKGROUND}

\section{A. External quantum efficiency of OLEDs}

The EQE of an OLED is given by four individual factors [8]:

\footnotetext{
*bruetting@physik.uni-augsburg.de
}

$$
\eta_{\mathrm{ext}}=\gamma \eta_{\mathrm{r}} q_{\mathrm{eff}} \eta_{\mathrm{out}} \equiv \eta_{\text {int }} \eta_{\mathrm{out}}
$$

Therein, $\gamma$ represents the charge carrier balance of electrons and holes. This factor is calculated from the ratio of the recombination and the total current flow and can be brought close to unity in state-of-the-art devices if lowbarrier charge carrier injection, appropriate blocking, and conductivity-doped transport layers are used [4,9-13].

The second factor of Eq. (1) takes into account the multiplicity of possible spin orientations in the excited state and is called the radiative exciton fraction. In a classical picture, the recombination of injected charges leads to $75 \%$ triplet excitons (with total spin $S=1$ of the electron-hole pair) and only $25 \%$ singlet excitons (with $S=0$ ). Therefore, classical fluorescent materials cannot overcome the limit of $25 \%$ for the internal quantum efficiency because the radiative decay of triplet excited states is forbidden according to spin-selection rules [1,14-18]. By contrast, phosphorescent emitter molecules based on metal-organic complexes with heavy-metal central atoms, such as iridium or platinum, profit from strong spin-orbit coupling lifting the strict spin-selection rules. They exhibit metal-to-ligand charge-transfer (MLCT) character, which, in turn, allows for fast intersystem crossing from the excited singlet level $S_{1}$ to the lowest excited triplet level $T_{1}$ and simultaneously efficient radiative decay from $T_{1}$ to the singlet ground state $S_{0}$. As a consequence, this type of emitting species allows for $100 \%$ radiative exciton fraction [2,19-26].

However, in recent years, strong efforts were made to overcome this drawback in fluorescent emitter molecules by using $e$ - or $p$-type delayed fluorescence [27-32]. An improved radiative exciton fraction and therewith high $\mathrm{EQE}$ values comparable to their phosphorescent 
counterparts have been obtained for thermally activated delayed fluorescence (TADF) emitter materials [33-38]. In contrast, EQEs for materials that utilize emission based on triplet-triplet annihilation (TTA) lag behind due to the bimolecular nature of this process, where inherently at least half of the excited triplet states are lost [39-47].

The probability that an allowed electronic transition from the excited state to the singlet ground state occurs radiatively is taken into account by the third factor contributing to the EQE, the radiative quantum efficiency $q_{\text {eff }}$. This factor strongly depends on the intrinsic quantum yield of photon emission from the excited state in the neat material $(q)$ and the feedback from the surrounding cavity if the emitter is embedded in a thin-film structure with partly and/ or highly reflecting interfaces [48-62] because the radiative rate and therewith the excited-state lifetime is modified by the Purcell effect [63]. It is worth noting that the Purcell factor strongly depends on the actual orientation of the transition dipole moment vectors (TDMVs) of the emitter molecules since the cavity induces, in a simplified picture, different interference conditions for vertical and horizontal dipole alignment with respect to the substrate plane [61,64]. Furthermore, current- and concentration-induced quenching processes during electrical operation at high currents can reduce this value resulting in the so-called efficiency roll-off of OLEDs [65-77]. These three individual factors are often combined to the internal quantum efficiency $\eta_{\text {int }}$ of an OLED device, which describes the process of converting electrical into optical power.

Finally, the last factor of the EQE equation specifies the fraction of internally generated optical power that can reach the outside world of an OLED and can, therefore, be used for lighting purposes. This outcoupling factor $\eta_{\text {out }}$ takes into account the power dissipation into different optical modes present in a thin-film-layered structure. Depending on the emission angle with respect to the substrate normal of the device, one can distinguish four different optical modes: direct emission, substrate modes (which can easily be extracted using outcoupling enhancement structures on the back side of a glass substrate), waveguided modes in high-index materials, such as the organic layers or the semitransparent oxide anode, and near-field coupling to surface-plasmon polaritons (SPPs) at the organic-metal interface $[52,64,78-81]$. Therefore, this factor strongly depends on the refractive indices and thicknesses of all individual layers, the position of the emitting species, i.e., the distance to the highly reflecting metallic cathode, absorption issues, and, of course, the distinct orientation of the TDMVs of the emitting molecules [61,64,81-83]. In a simplified picture (see Fig. 1), one can easily imagine that the radiation of a dipole is strongest perpendicular to its axis, thus, making horizontal dipole orientation, i.e., with their axis in the substrate plane, the desirable one.

In this review article, the power dissipation to different optical modes as a function of transition dipole alignment is

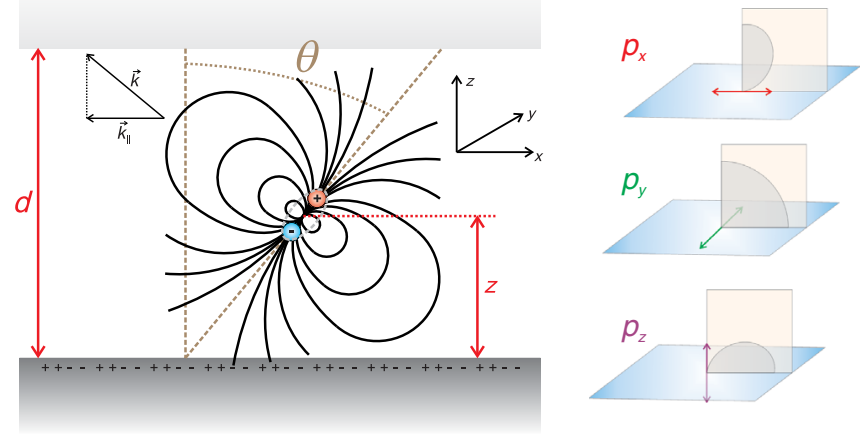

FIG. 1. Sketch of the physical parameters important for the power dissipation simulation of excited molecules in a microcavitylike structure (at the bottom, a metal layer is located). The excited state is treated as an oscillating electrical dipole pointing along the transition dipole moment vector of the emitting molecule. On the right side, the definition of the different emission polarizations is drawn.

discussed in detail in the following chapters. However, we want to note that there exist several other methods to enhance light outcoupling from OLEDs, e.g., using scattering layers, grating structures, and high-index coupling or recycling of SPPs by energy transfer to dye molecules $[84,85]$. An overview of the respective theories and advances using such strategies can be found in the review papers of Brütting et al. [86] or Gather and Reineke [87], respectively, but is not discussed here in detail. Furthermore, it should be noted that molecular orientation is crucial for almost all applications based on organic semiconductors, as this feature strongly influences not only the light emission of organic dyes but also the light propagation in stratified media due to birefringence [88-91] as well as their electrical properties due to orientation-dependent charge carrier transport and injection [92-103]. Moreover, light absorption and charge collection in organic solar cells are strongly influenced by molecular orientation of the active materials as well [104-114].

\section{B. Optical simulations}

All optical simulations presented in this article are based on the approach of Wasey and Barnes [51] solving the three-dimensional Maxwell equations for an ensemble of excited molecules treated as individually oscillating dipoles $[49,50]$ taking into account electrodynamic boundary conditions in stratified media. The subsequent application of a transfer-matrix formalism using the Fresnel coefficients for transmission and reflection at all involved interfaces finally results in the power dissipation spectra for the oscillating dipole ensemble under study. In terms of emitter orientation, it is crucial to simulate this power dissipation for three distinct dipole orientations with respect to the substrate plane ( $x-y$ plane). Hence, the $x$ and $y$ components are defined as horizontal, and the $z$ components as vertically oriented. Therewith, the polarization of these three different 
dipole orientations is already determined if one chooses the $x-z$ plane as the observation plane.

(i) $P_{\perp, \mathrm{TM}}$ : dipoles oriented perpendicular to the substrate plane (vertical, $z$ direction), which emit $p$-polarized [transverse-magnetic (TM)] light.

(ii) $P_{\|, \mathrm{TM}}$ : dipoles oriented parallel to the substrate plane (horizontal, $x$ direction), which emit $p$-polarized light, too.

(iii) $P_{\|, \mathrm{TE}}$ : dipoles oriented parallel to the substrate plane (horizontal, $y$ direction), which emit $s$-polarized [transverse-electric (TE)] light.

As we mention in the previous section, physical parameters that are important to solve these equations are the thicknesses of the involved layers $\left(d_{i}\right.$, where $d=\sum d_{i}$ is the cavity length of the device), their complex refractive indices $\left(n_{i}\right.$ and $\left.\kappa_{i}\right)$, the emitter's position inside the stack (especially the emitter-metal distance $z$ ), the orientation of the oscillating dipole, and the intrinsic radiative quantum efficiency $(q)$ of the excited dye molecule (doped into a host material). The whole situation is illustrated in Fig. 1.

Note that apart from the emitting dipoles, the other organic layers in an OLED-including the host for the emitter-can exhibit pronounced optical anisotropy as well, although they are usually noncrystalline. Thus, for the simulation, the simple $2 \times 2$ transfer-matrix formalism for isotropic media is not sufficient, but a $4 \times 4$ formulation has to be used. However, due to the absence of a preferential direction in the plane of the layers, the uniaxial simplification of it is sufficient here [89].

The power dissipation spectra (Fig. 2) can be visualized as a function of the emission wavelength, and the in-plane wave vector $\left(k_{\|}\right)$, which is the projection of the photon wave vector onto the $x-y$ plane giving the emission angle inside the OLED stack. Hence, one can distinguish between four regions in such a representation, which are separated by different conditions for total internal reflection at the involved interfaces. The first region is the direct emission, where the generated photons are allowed to escape the OLED stack directly. The second region corresponds to the substrate modes, which consists of light that underwent total internal reflection at the substrate-air interface and, thus, is trapped in the glass substrate. This fraction can be easily extracted by macroscopic outcoupling structures, such as half-ball lenses attached to the substrate. The third and the fourth regions are strongly dependent on the polarization and the wavelength of emission and represent waveguided modes in the high-index materials (the semitransparent ITO anode and the organic layers) and near-field coupling to surface-plasmon polaritons at the metal-organic interface, respectively. Figure 2 shows an exemplary heat map for an OLED stack containing a green emitter with horizontal and vertical alignment of the TDMVs, respectively, clearly demonstrating the different coupling to optical modes for both dipole orientations. From this picture, it is obvious that horizontal TDMV

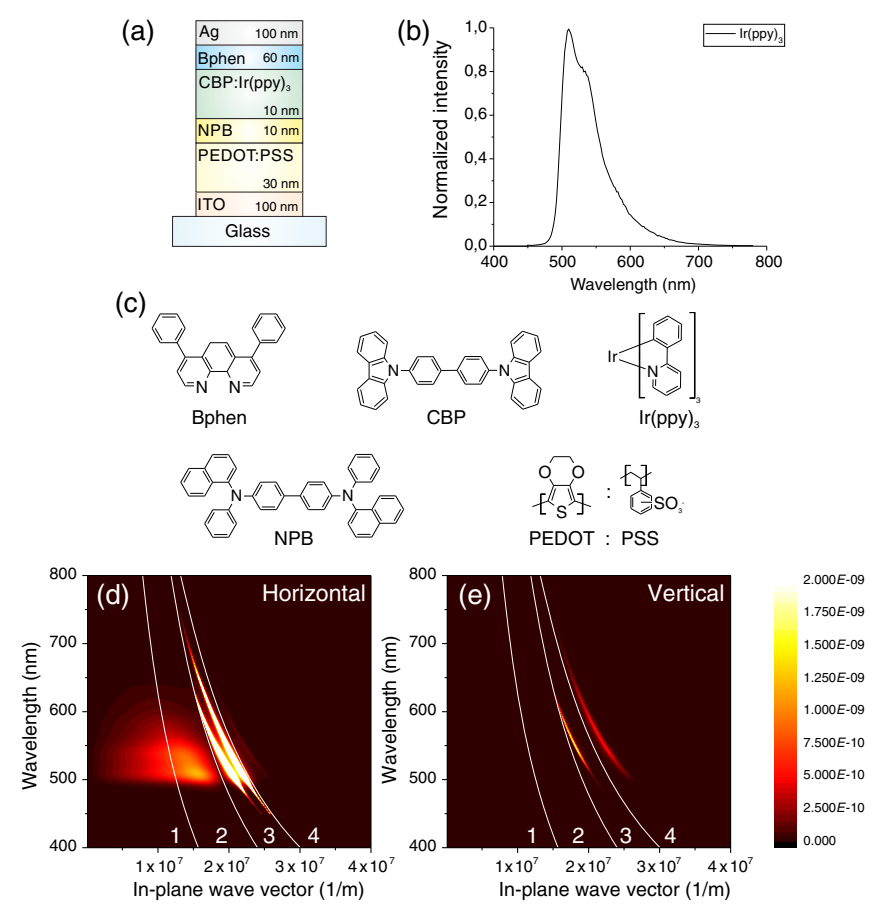

FIG. 2. (a) Exemplary OLED stack used for the following simulations. (b) Emission spectrum of the organic dye $\operatorname{Ir}(\mathrm{ppy})_{3}$. (c) Molecular structures of the organic materials used in (a). (d), (e) Power dissipation spectra as a function of the emission wavelength and the in-plane wave vector for a green-emitting OLED (a) with fixed-layer thicknesses for horizontal (d) and vertical (e) TDMV alignment. The heat maps are divided in four distinct sections: (1) direct emission, (2) substrate modes, (3) waveguided modes in high-index materials, and (4) nearfield coupling to surface-plasmon polaritons at the metal-organic interface.

alignment is the favorable one, as this leads to preferred coupling to optical modes, which can easily be extracted and therewith strongly enhance the external quantum efficiency of the device.

A more intuitive representation is given in Fig. 3. Here, the fraction of dissipated power to the individual optical modes is shown as a function of the electron-transport-layer (ETL) thickness for the same OLED as shown in Fig. 2 having a radiative quantum efficiency $q=1$ of the emitting system. For the different emitter orientations-isotropic, horizontal, and vertical-the power distributions show oscillations with a period of roughly one-fourth of the dominant emission wavelength with a decreasing amplitude for increasing ETL thickness because the cavity strength decreases with increased emitter-to-cathode distance. Because of different phase shifts for the reflections at the cathode-organic interface for vertical and horizontal dipole radiation, the corresponding maxima and minima for direct emission as well as for the Purcell factor (and therewith the excited-state lifetime) are displaced by one-eighth of the emission wavelength. Anyway, the outcoupling of light from horizontally aligned emissive 

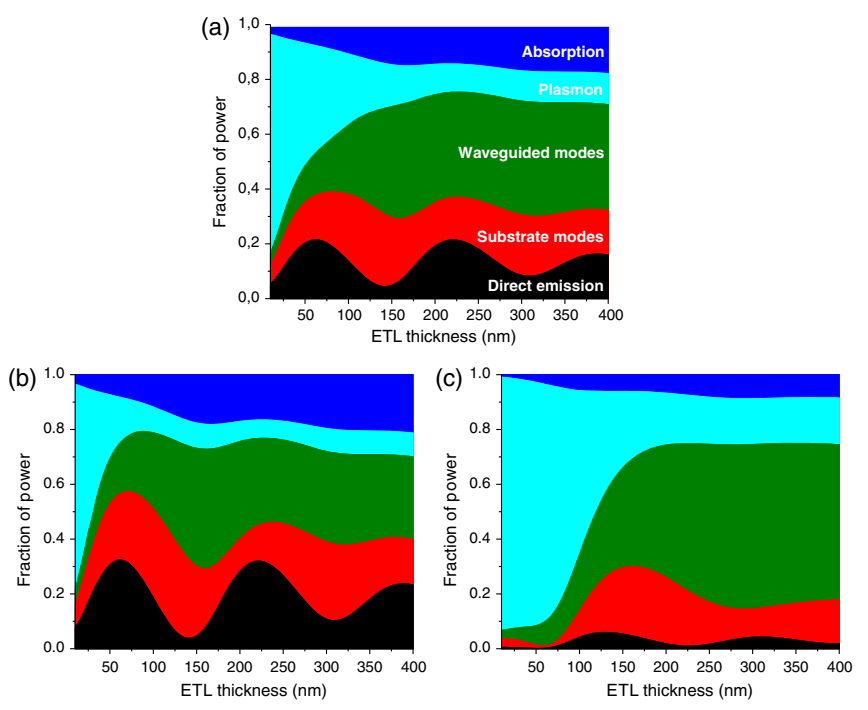

FIG. 3. Power dissipation to the different optical modes in the OLED stack of Fig. 2 with variable ETL thickness (emitter-tocathode distance) for (a) isotropic, (b) horizontal, and (c) vertical alignment of the emissive TDMVs.

dipoles is always higher compared to vertical ones for all ETL thicknesses. Therefore, if we use the expression "cavity maximum" in the following, we always mean the ETL thickness or emitter-to-cathode distance at which the maximum in light outcoupling for the horizontal TDMVs is reached.

Figure 3 emphasizes the already mentioned differences of power dissipation for the two extreme cases of transition dipole orientation. In particular, if the emitter is located close to the metallic cathode, most of the power generated by vertical TDMVs is lost due to near-field coupling to SPPs, while a huge part of the energy of the horizontally aligned emissive dipoles is directly extracted to air. Hence, if one compares the outcoupling factor for different orientations of the TDMVs, the horizontal alignment can outperform the isotropic case in thickness-optimized devices easily by a factor of $1.5[61,64,81,83,86]$.

We want to note that this graph also allows us to estimate the relative gain by emitter orientation for stacked or tandem OLEDs consisting of two (or more) individual units that are deposited on top of each other and electrically connected in series by a so-called charge-generation layer. Thereby, one can combine a blue (B) subunit with a redgreen- (RG) (i.e., orange) emitting subunit to achieve white. Or two RGB subunits are stacked on top of each other to reduce the drive current for a given brightness and, thus, enhance device lifetime. However, from an optical point of view, such tandem OLEDs can be easily treated by putting one emission zone in the first cavity maximum and the other in the second. For the green emitter used in the simulations of Fig. 3, the relative benefit between isotropic and horizontal orientation in the second cavity maximum is only slightly reduced as compared to the first one.
The reason is that the reduced coupling of vertical dipoles to SPPs in the second cavity maximum is almost completely compensated by their stronger dissipation of energy to waveguided modes.

We also want to note that emitter orientation can offer an additional degree of freedom in the design of tandem white OLEDs. For example, if only the red and green phosphors exhibit horizontal alignment, it is beneficial to place them in the first cavity maximum, while the isotropic blue phosphor sits in the second one. In this way, Lee et al. [115] have achieved a fully phosphorescent tandem white OLED with an EQE of more than 50\%. Or, in a hybrid white tandem OLED with fluorescent blue and phosphorescent red and green, it can be advantageous to place blue in the first maximum, in particular, if the fluorescent blue emitter is horizontally aligned and shows a significant TADF contribution [116].

Moreover, it should be pointed out that knowledge of the anisotropy of the TDMVs is required to perform a consistent efficiency analysis of OLED EQE values and the individual contributions of the four factors determining this quantity as outlined in Refs. [46,61,64,81,116,117] for several fluorescent- and phosphorescent-emitting systems.

The presented simulations not only highlight the potential efficiency increase due to favorable orientation of the TDMVs in organic light-emitting materials but are also used in the following to determine the actual degree of anisotropy, especially for doped guest-host systems containing fluorescent or phosphorescent dyes in an amorphous matrix material.

\section{Time-dependent density-functional-theory calculations}

To study the net orientation of the optical TDMVs of dyes in a host matrix, in addition to knowing how the molecule is oriented against the substrate, it is essential to know how the TDMV of the concerned optical transition is oriented with respect to the molecular frame of the dye. For transitions between electronic states having the same spin, TDMVs can be computed quite accurately within the framework of conventional quantum-chemistry methods that do not account for spin-orbit interactions. Therefore, the TDMV of the emissive transition in a fluorescent dye (typically $S_{1} \rightarrow S_{0}$ in accordance with Kasha's rule) can be calculated using conventional excited-state quantumchemistry methods that do not include spin-orbit coupling (SOC). However, in the absence of SOC, phosphorescent emission from triplet states to the singlet ground state are strictly forbidden, and, hence, the TDMVs of such transitions and other phosphorescent properties cannot be computed within such a framework. Several approaches to incorporate SOC within time-dependent densityfunctional theory (TDDFT) and other quantum-chemistry methods have been developed and implemented [118-131]. Among these, TDDFT with the relativistic ZORA 
(zero-order regular approximation) Hamiltonian [126-128] has been used in several studies to compute phosphorescent properties of heavy-metal complexes with high accuracy [132-136]. In a recent study, Kim et al. [137] used the ZORA approach within the TDDFT framework to compute the TDMVs $\left(T_{1} \rightarrow S_{0}\right)$ for a number of phosphorescent emitters. The ZORA equation is an approximation to the relativistic Dirac equation and is written as

$$
\begin{aligned}
H^{\mathrm{ZORA}} \Psi & =E \Psi \quad \text { with } \\
H^{\mathrm{ZORA}} & =V+\mathbf{p} \frac{c^{2}}{2 c^{2}-V} \mathbf{p}+\frac{c^{2}}{\left(2 c^{2}-V\right)^{2}} \boldsymbol{\sigma} \cdot(\boldsymbol{\nabla} V \times \mathbf{p}) .
\end{aligned}
$$

In the above expression, $V$ contains the nuclear and electronic Coulombic potentials and exchange-correlation potential, $\mathbf{p}$ is the momentum operator, $\boldsymbol{\sigma}$ denotes the Pauli matrices, and $c$ describes the speed of light. The third term of the Hamiltonian is the contribution from SOC. The ZORA approach can be used to compute the TDMVs involved in the transition from triplet states to the singlet ground state in phosphorescent dyes at a tractable cost.

We use the ZORA TDDFT approach (henceforth referred to as SOC TDDFT) to compute the TDMVs associated with the phosphorescent emission of several complexes; the results are discussed in Sec. VA 4. The ground-state geometry of all complexes reported here are calculated at the B3LYP-LACVP*** level. Starting from the optimized ground-state geometry, unrestricted DFT is employed to optimize the geometry of the triplet state without symmetry restrictions. The TDMVs are then computed from SOC TDDFT calculations performed using the ZORA Hamiltonian on the optimized triplet geometries of the complexes using the B3LYP functional and the DYALL2ZCVP-ZORA-J-PT-GEN basis set. All calculations are performed using the MATERIALS SCIENCE SUITE developed by Schrödinger [138]. It should also be noted that a consequence of SOC is the loss of degeneracy of the three sublevels of the triplet states, even in the absence of a magnetic field. Therefore, SOC will lead to phosphorescent emission at room temperature comprised of transitions from all three sublevels of the $T_{1}$ state, with each state having different oscillator strengths at slightly different energies (usually $<200 \mathrm{~cm}^{-1}$ apart from each other). It is often the case that a transition from one of the three triplet sublevels to the ground state will have an oscillator strength that is orders of magnitude larger than the other two and, thus, dictate the photophysical properties [139]. Hence, for the sake of simplicity, the TDMVs for emission from the other two sublevels are not shown in this work.

\section{METHODS TO DETERMINE EMITTER ORIENTATION}

There are several methods to determine the orientation distribution of the transition dipole moment vectors of organic molecules. However, all of them exhibit specific drawbacks and advantages or are not applicable to all sample structures. Hence, no single method is "perfect," and, thus, we present several different approaches in some detail.

\section{A. Variable-angle spectroscopic ellipsometry}

Variable-angle spectroscopic ellipsometry (VASE) measures the changes in polarization and phase for linearly polarized light that is reflected from a sample consisting of the layer of interest deposited on a reflective substrate, e.g., a silicon wafer. Here, one has to distinguish between electrical fields of the reflected, elliptically polarized light oriented perpendicular and parallel to the plane of incidence defined as ordinary and extraordinary, respectively. The results are analyzed by numerical simulation yielding the ordinary and extraordinary refractive indices and extinction coefficients as well as the thickness of the investigated layer [140]. From the obtained optical anisotropy of such films, it is possible to draw conclusions about the orientation of the TDMVs of the material. This approach has been applied to polymer films prepared by spin coating as well as small-molecule films deposited by vacuum evaporation [141-145]. The anisotropy of the TDMVs is connected to the order parameter $S$ [146], which is defined by the ordinary and extraordinary extinction coefficients $\kappa_{o}$ and $\kappa_{e}$, respectively,

$$
S=\frac{\kappa_{e}^{\max }-\kappa_{o}^{\max }}{\kappa_{e}^{\max }+2 \kappa_{o}^{\max }}=\frac{3\left\langle\cos ^{2} \theta\right\rangle-1}{2} .
$$

Therein, $\left\langle\cos ^{2} \theta\right\rangle$ indicates the quadratic average of the projection of the TDMVs of an ensemble of molecules, each carrying only one distinct TDMV with respect to the surface normal. Thus, completely horizontal alignment results in $S=-\frac{1}{2}$, isotropic distribution is indicated by $S=0$, and vertical orientation yields $S=1$. The drawback of this method is that the fit procedure strongly depends on the model used for describing the electronic response of the material, as well as being inapplicable to dilute guest-host systems.

\section{B. Polarization- and angle-dependent luminescence spectroscopy}

An alternative method to extract the orientation of the TDMVs, in particular, for dye-doped guest-host systems, is polarization- and angle-dependent luminescence spectroscopy, which can be applied to detect both photoluminescence (PL) from a thin emissive layer [147] as well as electroluminescence (EL) from a complete OLED stack $[83,148]$. As we mainly refer to PL spectroscopy in this article, the EL method is not explained in detail; in short, it requires a special OLED design using a cavity minimized for horizontal dipoles and the exact knowledge of all optical constants and thicknesses of the involved materials. Nevertheless, it is worth noting that angle-dependent EL 
spectroscopy is, furthermore, suitable to determine the emission zone profile in OLEDs [149-153].

To determine the orientation of TDMVs of organic dye molecules in neat layers or guest-host systems, one measures the $p$-polarized response of the emissive species as a function of the emission angle. A thin film on a glass substrate, which is index matched to a macroscopic halfcylinder prism, is mounted on a rotary stage (see Fig. 4) to detect the angle-dependent PL intensity with a spectrometer. The sample is excited using a continuous-wave laser with sufficiently short wavelength. The excitation spot size is less than $1 \mathrm{~mm}^{2}$.

Since the observation plane is given by the setup and is denoted as the $x-z$ plane, one can distinguish between $p$-polarized emission from the $x$ and $z$ dipoles as well as $s$-polarized emission from the $y$ dipoles, respectively (cf. Fig. 1). While horizontal dipoles couple most of their energy to direct emission, the vertical ones radiate mostly
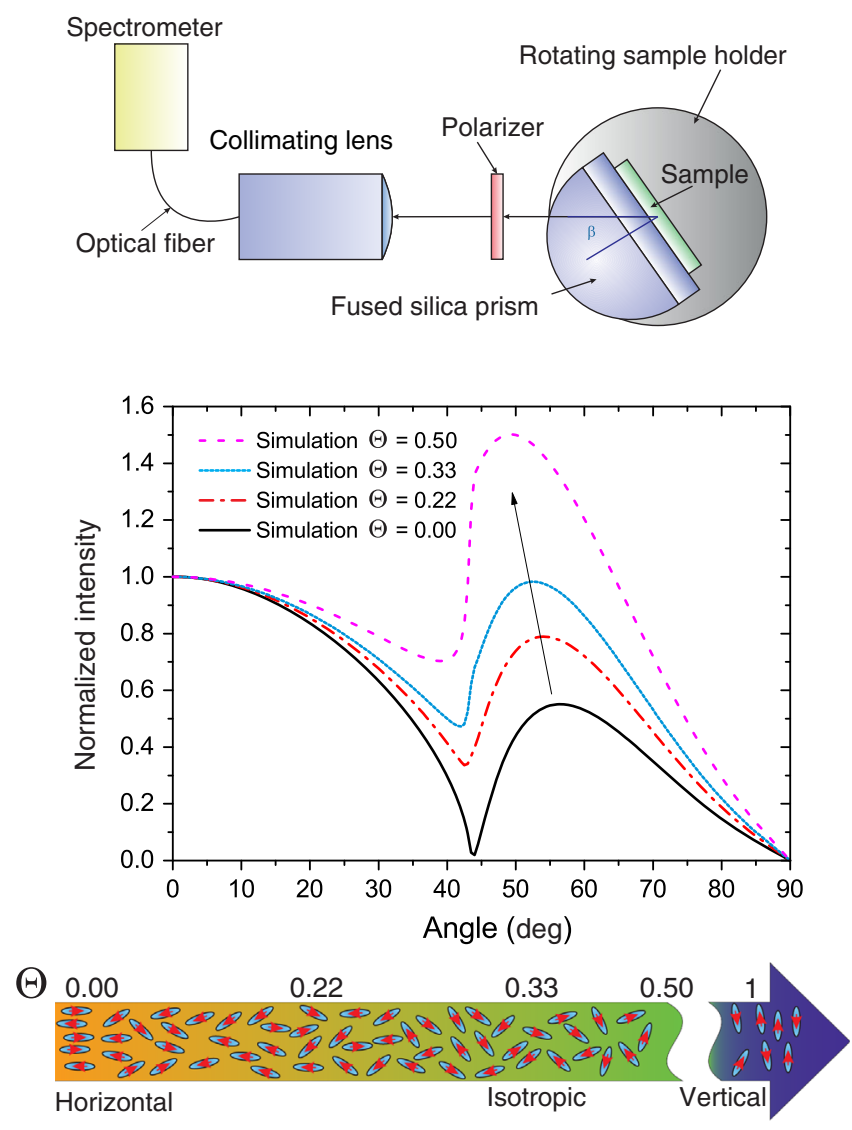

FIG. 4. Sketch of the angle- and polarization-dependent luminescence spectroscopy method used to determine the alignment of TDMVs of organic dye molecules in thin (doped) films. The middle row shows optical simulations of the angle-dependent photoluminescence response of the $p$-polarized emission for different ratios of vertically to horizontally oriented TDMVs. At the bottom, a schematic representation of the anisotropy factor is shown for rodlike molecules carrying their TDMV parallel to the long axis. into substrate modes $[64,147]$. Hence, the emission for angles higher than approximately $42^{\circ}$ (substrate modes extracted by the attached prism) can be used to quantify the relative ratio of horizontal to vertical dipoles (see Fig. 4). The measured intensity (normalized to zero degree emission) can then be fitted by optical simulations resulting in the anisotropy factor $\Theta$ [61], which is defined as follows:

$$
\Theta=\frac{\sum p_{z}^{2}}{\sum \vec{p}^{2}}=\left\langle\cos ^{2} \theta\right\rangle
$$

Therein, $\sum p_{z}^{2}$ denotes the sum over the emitted power by vertically oriented dipoles, $\sum \vec{p}^{2}$ represents the total emitted power by all emissive dipoles, and $\left\langle\cos ^{2} \theta\right\rangle$ stands for the average projection of the TDMVs onto the surface normal. Thus, completely horizontally aligned TDMVs result in $\Theta=0$, an isotropic distribution is given by $\Theta=0.33$, and vertical emitter orientation is indicated by $\Theta=1$. The order parameter $S$ introduced in the previous section can be connected to the anisotropy factor $\Theta$ in a straightforward manner:

$$
S=\frac{1}{2}(3 \Theta-1)
$$

Furthermore, to double check the accuracy of the outcome of the analysis, the $s$-polarized emission of the $y$ dipoles is fitted, too, and the results are considered to be reliable only if both simulations are consistent with one set of fitting parameters. This method is suitable to determine anisotropies of TDMV orientation for a wide range of emitter materials so long as the quantum efficiency is high enough to detect an optical signal by laser excitation. It is worth noting that for a consistent determination of the dipole orientation, the exact optical constants must be known, in particular, possible birefringence of the matrix material in a guest-host system.

\section{Excited-state lifetime near metal layers}

A third method to determine the orientation of transition dipole vectors in a light-emitting film or a complete OLED stack is to analyze the behavior of the excited-state lifetime with respect to the distance of the emitter to a highly reflecting metal layer, e.g., the cathode of an OLED. As already mentioned in previous sections, the Purcell effect in microcavity structures strongly changes the radiative rate from the excited state of organic dye molecules. Since the Purcell factor is determined by the cavity strength at the emitter position, it is strongly dependent on the orientation of the TDMVs, the cavity structure, and the distance of the emitting species to a metal interface. Since only the radiative rate is affected, a variation of the emitter-metal distance can be used to extract the radiative quantum efficiency of the emitter material. This technique was introduced by Drexhage [54,55] to analyze the quantum 


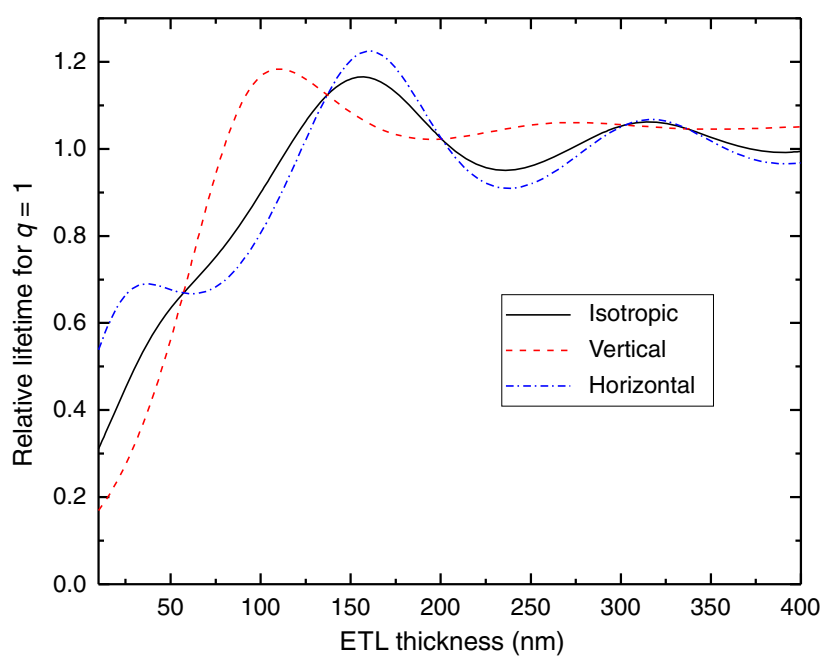

FIG. 5. Simulation of the change in relative excited lifetimes of a green-emitting material exhibiting perfect radiative quantum efficiency in the aforementioned OLED stack (Fig. 2) for different orientations of the TDMVs and as a function of the ETL thickness, corresponding to the emitter-to-metal distance.

yield of dye molecules and was later extended to obtain additional information on their TDMV orientation by Garrett et al. [154]. Recently, this technique was extended to complete OLED structures by varying the electrontransport layer thickness, i.e., the emitter-to-cathode distance, to analyze both the radiative quantum efficiency and the orientation of the emissive TDMVs $[60,61,64,81,86]$, as well as the exciton quenching induced by the current $[74,76]$. Figure 5 shows simulated excited-state lifetime changes relative to the intrinsic value in the absence of any cavity effects for three different orientations of the TDMVs of a green emitter material. The different interference conditions for vertically and horizontally aligned dipoles can easily be seen in this simulation. Where horizontal dipoles exhibit a maximum in the excited-state lifetime, the vertical ones are close to a minimum and vice versa. The differences between isotropic and horizontal orientation are most significant for small distances of the emitter to the metal interface (less than about $50 \mathrm{~nm}$ ). Thus, it is important to properly design the experiment by choosing spacer thicknesses that allow for a distinction between different orientations. Furthermore, the optical simulation program should be able to deal with the peculiarities of dipoles in close proximity of a metal layer, i.e., the coupling to SPPs as well as lossy surface waves [48,78,155]. Although the stack layout is further optimized to enhance sensitivity [156], the technique still suffers from considerable inaccuracies and should, therefore, be combined with other methods.

\section{External quantum-efficiency measurements using macroextractors}

As we show in previous sections, the coupling to the optical modes of an OLED for varying cavity length, i.e.,

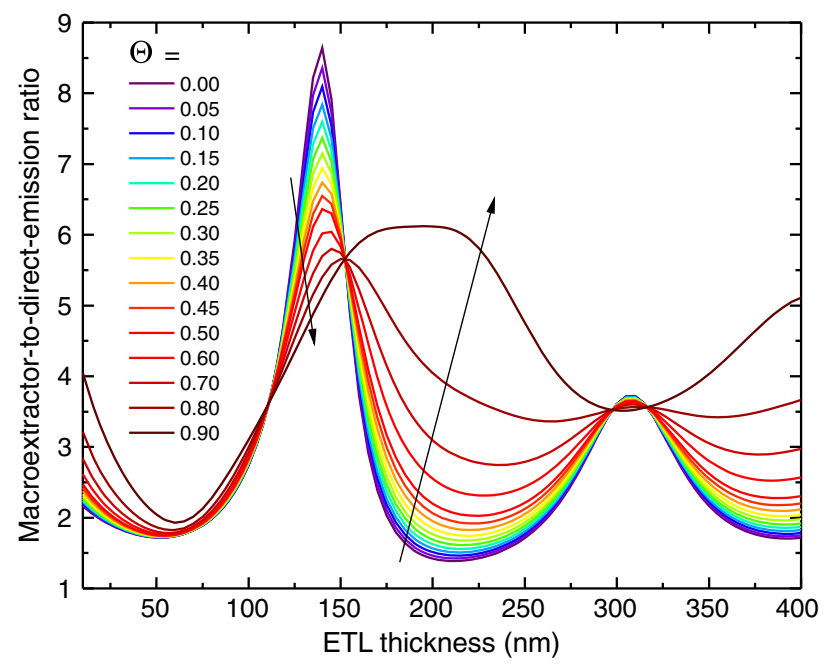

FIG. 6. Optical simulations of the ratio of substrate mode to direct emission for the already mentioned OLED stack (Fig. 2) with variable ETL thickness and therewith variable emitter-tocathode distance. The colors indicate different alignment of the TDMVs.

emitter-to-cathode distance, exhibits strong variations between different TDMV alignment. This feature can be used to extract the emitter orientation in OLEDs using a series of devices with varying ETL thickness by simple EQE measurements [157]. Therefore, one has to measure the $\mathrm{EQE}$ in an integrating sphere with and without a macroextractor to separate the contributions of direct emission and substrate modes. As the power dissipation to these two easily accessible optical modes is strongly dependent on the orientation of the TDMVs, the ratio of both quantities exhibits a unique behavior. Figure 6 shows simulations of this quantity for a green-emitting OLED structure for different emitter orientations as a function of the ETL thickness. Comparing measurements with these simulations allows for the determination of the emissive dipole alignment. Interestingly, this method can be applied for various current densities and does not depend on the internal quantum efficiency of the OLEDs [157]. Thus, it is applicable for all emitting systems so long as an accurate $\mathrm{EQE}$ measurement is possible. Furthermore, the method requires exact knowledge of the optical constants and the thicknesses of all layers of the OLED and a set of samples with varying ETL thickness. Hence, this method is not widely used in the community, although the accuracy can be comparable with the first two presented methods; however, the experimental effort is typically higher.

\section{E. Absorption measurements before and after thermal annealing}

All of the methods presented so far require fitting the measured results with simulations using appropriate models, which, in turn, can easily lead to inaccurate or even 
wrong results if the model itself is inappropriate. Recently, Sakai et al. [158] presented a model-free technique to determine TDMV orientation. They used the fact that molecular alignment vanishes if the films are thermally annealed above their glass transition temperature $T_{g}$, provided that the host material does not crystallize $[100,159,160]$. Comparing simple absorption measurements of as-prepared and postannealed films allows us to calculate the order parameter $S$ from the correspondingly measured absorbances $A$ and $A_{0}$, respectively, and assuming that the postannealed film shows perfectly isotropic orientation of the TDMVs:

$$
S=1-\frac{A}{A_{0}} .
$$

With this simple approach, it is possible to determine the alignment of the TDMVs not only for neat films but also for doped guest-host systems if the absorbance of the two materials strongly differs in their wavelength response.

Another possible way to use this approach is to compare the absorbance of films prepared from thermal evaporation with the ones fabricated from solution, e.g., by spin coating. However, this is possible only for small-molecule material systems showing isotropic behavior when prepared from solution.

\section{RESULTS (1): FLUORESCENT EMITTERS}

\section{A. Emitter orientation in fluorescent small-molecule guest-host systems}

The observation of alignment of the TDMVs in neat films [92] has led to pronounced efforts to detect such anisotropies for doped small-molecule emissive films typically used in OLED applications, too. Unfortunately, most of the common methods are not applicable, as they analyze only the orientation of the host, and, thus, information about the dye molecules cannot be obtained. An initial experiment [161] used the edge emission of waveguided light in guest-host systems, i.e., the part of the emission parallel to the substrate plane [162] that was previously used to determine the alignment of polymers [163-168] to gain information of TDMV alignment in a doped small-molecule layer. It was shown that the emitting molecule BSB-Cz [4,4'-bis[(N-carbazole)styryl]biphenyl] doped in an $\mathrm{Alq}_{3}$ [Tris-(8-hydroxyquinoline)aluminum] matrix displays pronounced orientation of its TDMVs in the substrate plane [161]. However, as this technique needs a significant effort in both measurement and simulation, it has not been frequently used. The technique was replaced shortly thereafter by a polarization- and angle-dependent photoluminescence spectroscopy procedure invented by Frischeisen et al. [147], as this latter method was found to be more accurate.

Using this new technique, the same authors were able to analyze the direct influence of the alignment of
TDMVs in OLEDs [82]. Therefore, they used two different dye molecules, 4,4'-bis[4-(diphenylamino)styryl]biphenyl (BDASBi) and 4-(2,2-diphenylethenyl)- $N, N$-bis(4-methylphenyl)benzenamine (PEBA), that exhibit near-identical emission spectra in the sky-blue spectral range and have comparable photoluminescence quantum yield of 0.65 and 0.55 , respectively, when doped with $6 \mathrm{wt} \%$ in a $4,4^{\prime}-$ bis $(N$ carbazole)-biphenyl (CBP) matrix. The influence of different orientations of the TDMVs on the outcoupling efficiency can be directly probed using these dyes because they do not markedly affect the electrical characteristics of the fabricated OLEDs. The external quantum efficiency of the BDASBi devices were higher than the PEBA devices, which was presumed to originate from improved outcoupling efficiency due to emitter orientation. The TDMVs of PEBA are isotropically distributed in the doped film, whereas the TDMVs of the elongated molecule BDASBi exhibit a strong preferential horizontal alignment with respect to the substrate plane $(\Theta=0.12)$, yielding an increased light outcoupling by a factor of 1.45 . As densityfunctional-theory simulations reveal a parallel orientation of the TDMV along the long axis of the BDASBi molecule, this means that the molecule itself is aligned mainly parallel to the substrate plane. Therewith, it was shown that strongly anisotropic molecular shapes, i.e., long-rod style, show preferential horizontal alignment not only in neat films but also if doped into an amorphous matrix material such as CBP.

Although, the absolute values of the external quantum efficiencies of the devices in that study were relatively low, these results were the starting point for extensive research on molecular, i.e., TDMV, alignment for OLED efficiency enhancement.

Classical fluorescent emitters suffer from their low radiative exciton fraction, as only $25 \%$ of all electrically generated excited states are allowed to decay radiatively. Thus, the internal quantum efficiency of OLEDs using such materials is limited to $25 \%$, and even perfect horizontal alignment of the TDMVs, which results in an outcoupling factor near 35\%, is not able to reach EQE values as high as those achieved by conventional phosphorescent-emitting systems.

Hence, new classes of fluorescent emitters are being developed to combine both preferential alignment of their TDMVs to enhance light outcoupling, as well as an increased radiative exciton fraction by using $e$ - or $p$-type delayed fluorescence. Although the basic underlying mechanisms to achieve delayed fluorescence, and, thereby, harvest triplet excitons by transforming them into singlet excited states, are different, both types of materials can profit from nonisotropic emitter orientation induced by molecular shape, even in doped films.

There are several publications dealing with using the TTA process ( $p$ type) to achieve extraordinary high EQE for OLEDs that are close to or even exceed the stated 
limit of their theoretical possible efficiencies of $1 \times 0.625 \times 1 \times 0.2=12.5 \%$. Therein, the classical $20 \%$ outcoupling efficiency for isotropic TDMV orientation and the radiative exciton fraction $\eta_{r}$ is enhanced by $0.5 \times 0.75=37.5 \%$ [40], as only one singlet excited state is formed for every two triplet excitons, resulting in an overall value of $62.5 \%$. Most of the examples in the literature use anthracene derivatives $[42,169,170]$ or coumarin-based dyes [41,43,46,171,172]. However, few of these reports have taken into account possible deviation from random TDMV distributions in the analyzed OLEDs $[42,46]$, which can explain the high EQEs achieved by both types of emitting species (in the range of $7 \%$ ) [42,46,173].

While research using $p$-type delayed fluorescence for enhancing the efficiency in OLEDs is sparse, efforts using $e$-type delayed fluorescence systems are rather extensive. In the past ten years, this special class of fluorescent emitters that recycle triplet excitons by thermally activated back transfer to singlet excited states has made tremendous progress and even reached efficiencies comparable to the best phosphorescent devices [33-37,117,174-184]. Although several published articles claim internal quantum efficiencies close to the limit of unity, possible anisotropies of the TDMVs of the emitting species leading to higher light outcoupling efficiency were not considered and could lead to an overestimation of the radiative exciton fraction in these devices. In particular, the donor-acceptor approach used for such $e$-type-emitting molecules can emphasize preferential horizontal alignment due to the elongated shape of the molecules.

Altogether, the results achieved thus far emphasize the important contribution of TDMV alignment to the external quantum efficiency of fluorescent emitters, including molecules exhibiting delayed fluorescence. As a short overview, selected systems showing preferential orientation of their transition dipole moment vectors together with achieved external quantum efficiencies are summarized in Table I.

\section{B. Control of emitter orientation}

Up to this point, only "accidental" deviations from isotropy are discussed in this article. Although some molecules already show strong horizontal alignment of their TDMVs, to achieve even better OLED performance with respect to external quantum efficiency, one has to manipulate the molecular orientation to harvest the full potential of this effect. This section shows some promising examples of how to influence molecular orientation resulting in the desired horizontal alignment.

\section{Molecular shape}

One approach to control the orientation of molecules is to tailor their shape to a favorable one, i.e., rodlike linear appearance. Yokoyama et al. [161] studied the influence of length and end groups in such molecules. They used VASE to analyze the order parameter for CBP [4,4'-bis(carbazol9 -yl)biphenyl], a relatively short molecule. Styrylbenzene derivatives having carbazole or diphenylamine as bulky groups at both ends of the respective molecules were also examined in order to change the intermolecular interactions as well as the interaction with underlying layers. The longest molecule was the BSB-Cz molecule, which was already mentioned at the beginning of this section. First of all, they found that molecular orientation strongly depends on the substituents at both ends of the molecule. Intermolecular interactions between molecules with bulky end groups, as well as with the underlying layer, are based solely on weak van der Waals forces, resulting in surface energy minimization and, thus, horizontal alignment. In contrast, if these rather bulky groups are exchanged by, e.g., methyl groups, the picture changes. Although these molecules can still show horizontal alignment if their shape is long enough, van der Waals interactions between the molecules as well as with the underlying substrate can promote aggregation or build up crystalline phases resulting in pronounced vertical orientation of the molecules. Furthermore, horizontal alignment of the molecules with bulky substituents becomes stronger with increasing length of the molecule, e.g. the shortest molecule CBP showed isotropic orientation $(S=0)$, whereas the longest molecule (BSB-Cz) exhibited the lowest order parameter $(S=-0.33)$, i.e., near perfect horizontal alignment. Moreover, the authors stated that the horizontal orientation found for the neat films was conserved if the dye is codeposited by thermal evaporation in vacuum with an amorphous host. A sketch of the different situations of interaction is illustrated in Fig. 7.

Unfortunately, optical and electrical properties of the compounds are also typically changed upon altering the molecular shape. To combine the favorable shape and the desired functionality of new molecules is, hence, a present and future challenge for modern chemistry. As a

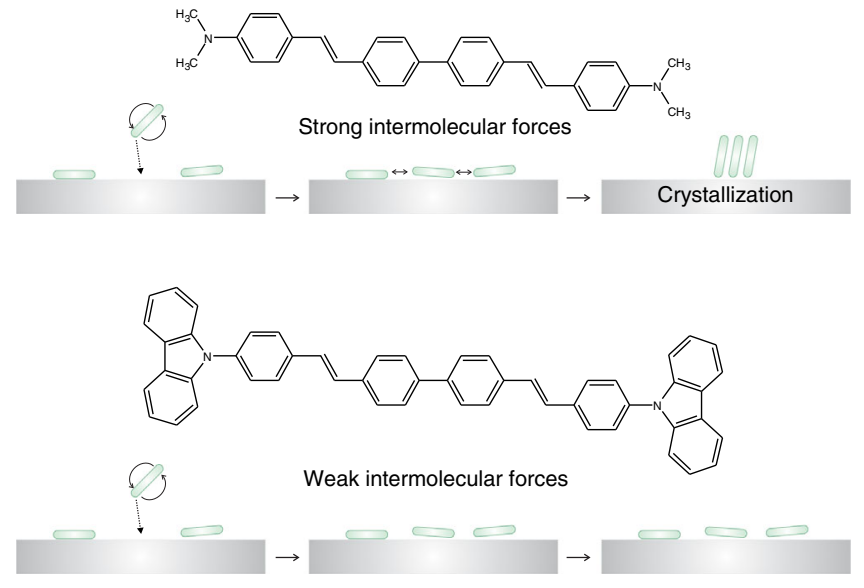

FIG. 7. Sketch of the alignment process of molecules with different substituents and therewith different intermolecular interactions for neat films (adapted from Ref. [161]). 
TABLE I. Exemplary list of fluorescent molecules showing pronounced horizontal emitter orientation.

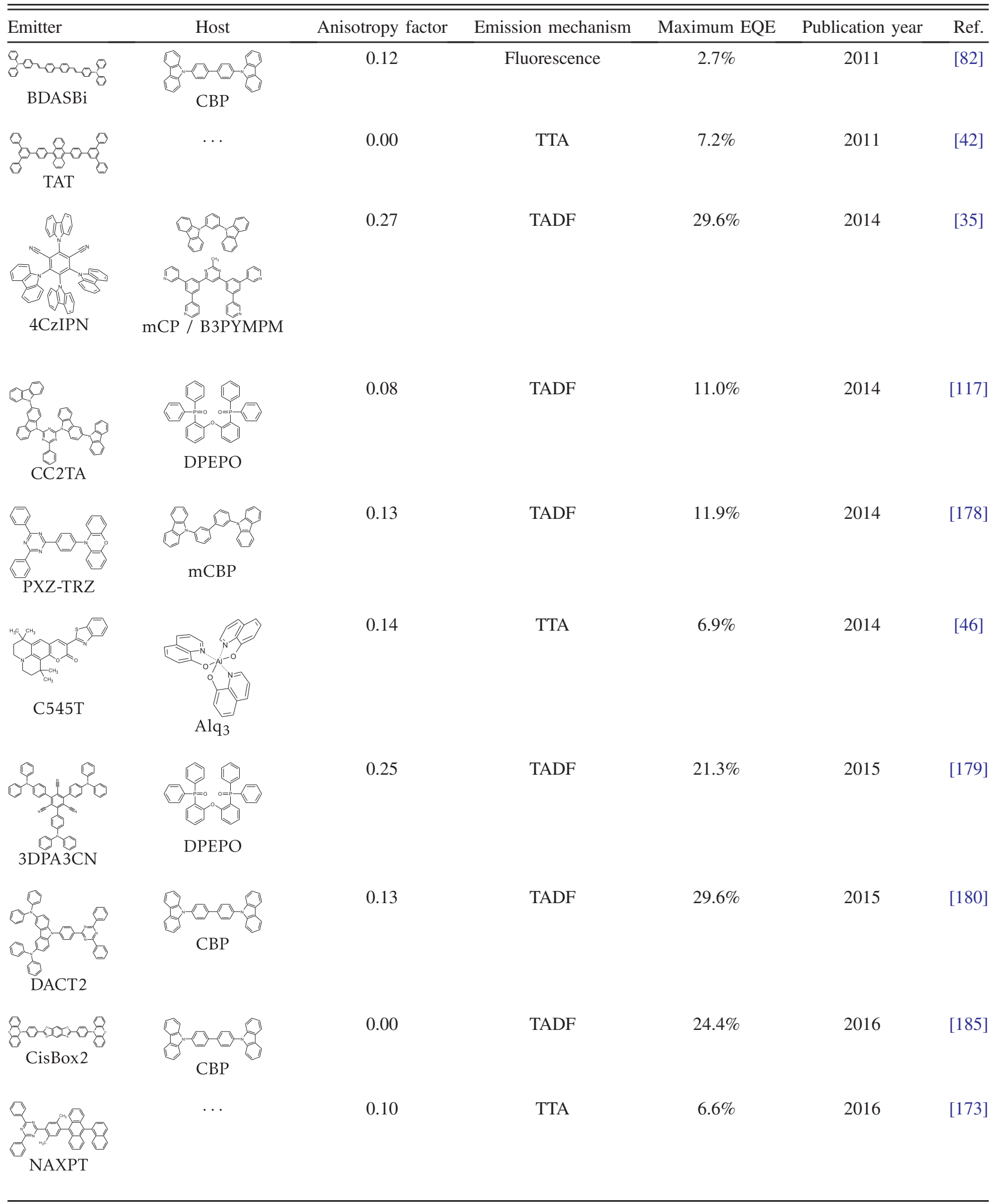


TABLE I. (Continued)

\begin{tabular}{|c|c|c|c|c|c|c|}
\hline Emitter & Host & Anisotropy factor & Emission mechanism & Maximum EQE & Publication year & Ref. \\
\hline & & 0.25 & TADF & $24.1 \%$ & 2017 & {$[186]$} \\
\hline
\end{tabular}

rule of thumb, to obtain low- $\Theta$ value, molecules should show weak intermolecular interactions and exhibit a pronounced linear shape provided the TDMV is oriented along the long axis of the molecule.

Another phenomenon was discovered by Kim and coworkers [186] who investigated the dependence of the preferential alignment to the aspect ratio of emitter molecules. In this work, two donor and two acceptor groups were attached to a phenyl linker at different positions, forming a molecule with TADF capabilities. The resultant dyes show different molecular geometries as well as $\Theta$ values of 0.29 to 0.15 . The metasubstitution of the donor moiety was identified as the most beneficial one because it combines molecular alignment with a high emitter quantum efficiency. Thus, they concluded that the aspect ratio of such molecules is a crucial factor for the formation of preferential alignment. These findings give further design rules for future TADF dyes.

\section{Film growth kinetics}

A promising technique to manipulate or even control the alignment of fluorescent molecules in both neat films and doped guest-host systems is using molecular dynamics at the surface of a growing film fabricated by thermal evaporation.

Several studies of molecular glasses have shown that preparing films by thermal evaporation under high vacuum leads to superior physical properties when compared to solution-processed samples, e.g., higher packing density [187], lower enthalpies [188], and lower tendencies for reorganization by postprocess thermal annealing [189-191]. These features can be further enhanced if the substrate temperature during vapor deposition is held below the glass transition temperature $\left(T_{g}\right)$ of the used material [160,192,193]. Analyzing the underlying mechanisms in greater detail reveals that molecular orientation processes predominantly occur at the free surface of the film, as molecules on the surface exhibit molecular diffusivities that are several orders of magnitude higher compared to molecules in the bulk, i.e., after being covered by several monolayers [100,194-199]. Dalal et al. [160] found that for neat molecular glasses, the anisotropy is strongly dependent on the substrate temperature during deposition and can be divided into three different temperature regimes related to the bulk glass transition temperature. If the substrate temperature $\left(T_{s}\right)$ is higher than $T_{g}$, the deposited molecules show isotropic distribution. For $T_{g}>T_{s}>0.9 T_{g}$, a slight preferential vertical alignment of the molecules is observed. Upon further decreasing the substrate temperature, the alignment becomes horizontal, which is the favorable orientation for OLED applications.

These findings have important consequences for the future manipulation of anisotropy in both neat as well as twocomponent mixed organic thin films prepared by thermal evaporation. Since we focus on emitter orientation in this article, we concentrate on the latter case in the following. Molecular orientation takes place only at the free surface during deposition and is frozen in the bulk material. One can enhance or depress the molecular mobility on the surface by either controlling the substrate temperature during deposition $[178,193]$ or by choosing the glass transition temperature of the matrix material in a favorable way [200].

Komino et al. [178] investigated the alignment of the TADF material 10-[4-(4,6-diphenyl-1,3,5-triazin-2-yl) phenyl]-10H-phenoxazine (PXZ-TRZ) doped into 3,3-di (9H-carbazol-9-yl)biphenyl (mCBP) during deposition for successively different substrate temperatures between 300 and $200 \mathrm{~K}$ [178]. The anisotropy factor of the TDMV of the PXZ-TRZ molecules decreased from isotropic distribution $(\Theta=0.33)$ to preferential horizontal alignment $(\Theta=0.13)$ as the substrate temperature was decreased from 300 to $200 \mathrm{~K}$. Consequently, they fabricated complete OLED stacks with the emission layer deposited at different substrate temperatures, and all other layers evaporated at room temperature. The electric characteristics of these OLEDs were all similar, which allowed for direct investigation of changes in light outcoupling due to different orientations of the TDMVs induced by cooling the substrate during processing of the EML. Therewith, the EQE was increased by the preferential horizontal alignment of the TDMVs from $9.5 \%$ to $12 \%$, a remarkable $30 \%$ enhancement.

Mayr and Brütting [200] used a different approach to change molecular alignment of dyes in amorphous hosts by varying the glass transition temperature of the matrix material. They used the classical fluorescent laser dye 


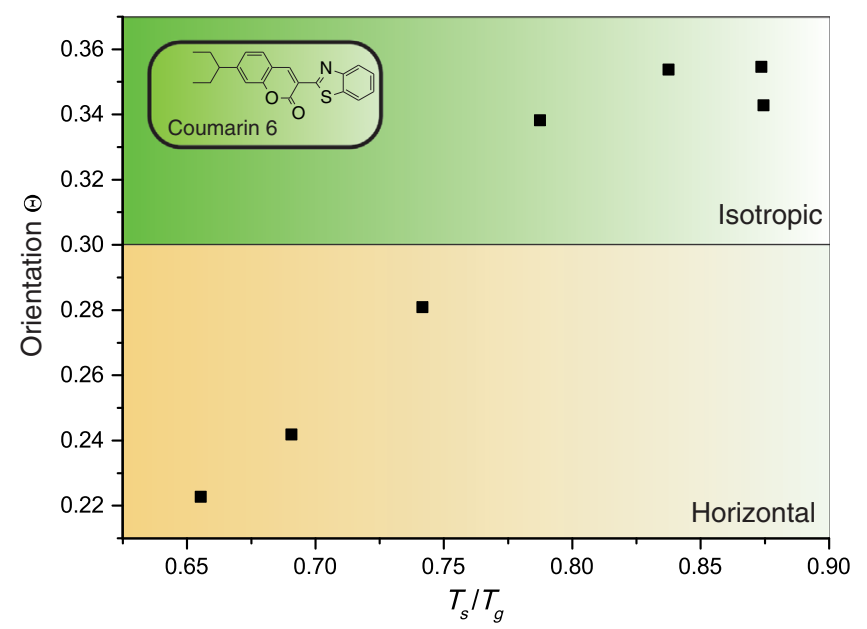

FIG. 8. Emitter orientation of the fluorescent dye Coumarin 6 as a function of the substrate temperature normalized by the glass transition temperature of the used amorphous matrix material (data taken from Ref. [200]).

Coumarin 6 [3-(2-benzothiazolyl)-7-(diethylamino)coumarin] and doped it in several different matrix materials at a doping concentration of $1 \mathrm{wt} \%$. The matrix material with the lowest glass transition temperature of roughly $333 \mathrm{~K}$ was CBP, while the matrix material with the highest glass transition temperature of $447 \mathrm{~K}$ was Spiro-2CBP. The orientation of the TDMVs of the Coumarin 6 molecules was again checked by angular-dependent emission spectroscopy. While nearly perfect isotropic distribution $(\Theta=0.34)$ of the TDMVs is achieved if Coumarin 6 is doped into CBP, a predominant horizontal alignment is observed in a Spiro-2CBP matrix $(\Theta=0.22)$. There is a near-linear trend if the anisotropy factors are plotted as a function of the substrate temperature normalized to the glass transition temperature of the corresponding matrix materials (see Fig. 8).

Both investigations are in agreement with the experimental and theoretical findings by the Ediger group in their model of alignment in anisotropic molecular glasses $[160,193,198]$. This, in turn, should facilitate achieving favorable emitter orientation for fluorescent OLEDs in future applications.

\section{Getting closer to the optimum value}

Recently, Komino et al. [185] succeeded in manipulating the alignment of the TADF molecule 2,6-bis[4-(10Hphenoxazin-10-yl)phenyl]benzo[1,2-d:5,4-d0]bis(oxazole) (cis-BOX2) realizing perfect horizontal alignment of its TDMVs if doped into CBP. It had been reported earlier that if $\mathrm{mCBP}$ is used as the host matrix, external quantum efficiencies as high as $17 \%$ [201] can be achieved in OLED devices. However, by subsequently cooling the substrate to $200 \mathrm{~K}$ during deposition of the emitting system cisBOX2:CBP (6 wt \%), they achieved perfect alignment of the emissive dipole moments with an anisotropy factor of $\Theta=0.0$, whereas an isotropic emitter orientation is realized if fabricated at a substrate temperature of $370 \mathrm{~K}$. Furthermore, they showed that alignment can be randomized again by postfabrication thermal annealing of the doped films resulting in isotropic orientation if heated up to $380 \mathrm{~K}$. Consequently, OLEDs were fabricated on a cooled substrate by evaporation of the emitting system consisting of cis-BOX2 and CBP. Impressively, they obtained a direct emission external quantum efficiency of $33.4 \%$ using both the TADF effect for an enhanced internal quantum efficiency and horizontal alignment of the TDMVs of the cisBOX2 molecules for an increased outcoupling factor of over $30 \%$.

These results clearly demonstrate the importance of horizontal alignment of the emissive TDMVs for fluorescent dye molecules. By aligning the dopant, fluorescent OLEDs can compete with efficiencies achieved for devices using phosphorescent-emitting systems.

\section{RESULTS (2): PHOSPHORESCENT EMITTERS}

\section{A. Emitter orientation in phosphorescent guest-host systems based on iridium complexes}

In this section, we focus on alignment of TDMVs for phosphorescent molecules based on heavy-metal complexes, particularly those of iridium. Three bidentate organic ligands are typically connected to the central Ir atom in an octahedral fashion, and every ligand is connected to the metal center via two bonds. Strong spin-orbit coupling induced by the heavy Ir atom leads to mixing of eigenfunctions between energy levels with different multiplicities (i.e., singlet and triplet states) resulting in enhanced phosphorescent emission. Because of the different spatial distributions of the involved orbitals, these transitions typically exhibit charge transfer from the metal center to the ligand (MLCT character) [139,202-207]. Thus, the transition dipole moment vector is pointing from the Ir atom towards the emitting organic ligand. However, when compared to fluorescent organic molecules, which are usually associated with only one emissive TDMV, the situation gets more complicated in these metal complexes due to the presence of multiple ligands which may have equal probabilities for emission. The triplet state has the choice to be localized on any one of the emissive ligands, and, in fact, it has been recently proposed that the triplet state fluctuates between the emissive ligands [208] before eventually emitting out of one of them. It is, therefore, difficult for the molecules to be oriented such that all the associated TDMVs lie parallel to the substrate in order to achieve favorable $\Theta$ values.

\section{Iridium complexes exhibiting deviations from isotropy}

For a long time, phosphorescent emission from organometallic Ir complexes was believed to be isotropic since the 
TABLE II. Exemplary list of phosphorescent molecules based on iridium central metal atoms showing pronounced nonisotropic emitter orientation [EQE values marked with (TE) are achieved for top emitting devices].

\begin{tabular}{|c|c|c|c|c|}
\hline Emitter & Anisotropy factor & Maximum EQE & Publication year & Reference \\
\hline \multicolumn{5}{|l|}{ Heteroleptic complexes } \\
\hline \multirow{4}{*}{$\operatorname{Ir}(\mathrm{mdq})_{2}(\mathrm{acac})$} & 0.23 & 18.7 & 2011 & {$[83]$} \\
\hline & 0.24 & $\cdots$ & 2014 & [209] \\
\hline & 0.23 & 27.1 & 2014 & [219] \\
\hline & 0.25 & $\ldots$ & 2016 & {$[210]$} \\
\hline \multirow{6}{*}{$\operatorname{Ir}(\mathrm{ppy})_{2}(\mathrm{acac})$} & 0.25 & 21.7 & 2012 & {$[211]$} \\
\hline & 0.23 & 29.7 & 2013 & {$[220]$} \\
\hline & 0.24 & 30.0 & 2014 & [221] \\
\hline & 0.23 & $\ldots$ & 2014 & [209] \\
\hline & 0.24 & $17.8(\mathrm{TE})$ & 2015 & {$[212]$} \\
\hline & 0.24 & $\ldots$ & 2016 & [210] \\
\hline \multirow{4}{*}{$\operatorname{Ir}(\mathrm{ppy})_{2}(\mathrm{tmd})$} & 0.22 & 32.3 & 2014 & {$[221]$} \\
\hline & 0.22 & 32.0 & 2014 & [115] \\
\hline & 0.24 & 27.6 (TE) & 2014 & [213] \\
\hline & 0.23 & 28.8 & 2015 & {$[214]$} \\
\hline \multirow{2}{*}{$\operatorname{Ir}(\mathrm{mphmq})_{2}(\mathrm{tmd})$} & 0.18 & 32.0 & 2014 & [115] \\
\hline & 0.18 & 35.6 & 2014 & [219] \\
\hline $\operatorname{Ir}(\mathrm{mphq})_{2}(\mathrm{acac})$ & 0.23 & 27.6 & 2014 & [219] \\
\hline $\operatorname{Ir}(\text { dhfpy })_{2}($ acac $)$ & 0.25 & $\ldots$ & 2014 & [209] \\
\hline $\operatorname{Ir}(\mathrm{BT})_{2}(\mathrm{acac})$ & 0.22 & $\cdots$ & 2014 & [209] \\
\hline FIr(pic) & 0.24 & 29.5 & 2014 & [222] \\
\hline $\operatorname{Ir}(3-\mathrm{mppy})_{2}(\mathrm{tmd})$ & 0.26 & 30.5 & 2015 & [223] \\
\hline $\operatorname{Ir}(4-m p p y){ }_{2}(\mathrm{tmd})$ & 0.25 & 31.9 & 2015 & {$[223]$} \\
\hline $\operatorname{Ir}(5-\mathrm{mppy})_{2}(\mathrm{tmd})$ & 0.23 & 32.0 & 2015 & [223] \\
\hline $\operatorname{Ir}\left(3^{\prime}, 4^{\prime}, 5-\mathrm{mppy}\right)_{2}(\mathrm{tmd})$ & 0.20 & 34.1 & 2015 & [223] \\
\hline $\operatorname{Ir}(\mathrm{ppm})_{2}(\mathrm{acac})$ & 0.24 & 26.8 & 2015 & [215] \\
\hline $\operatorname{Ir}(\mathrm{dmppm})_{2}(\mathrm{acac})$ & 0.22 & 28.2 & 2015 & {$[215]$} \\
\hline $\operatorname{Ir}(\mathrm{tBuCn}-\mathrm{F})_{2}(\mathrm{acac})$ & 0.23 & 22.3 & 2015 & [216] \\
\hline $\mathrm{Ir}(\mathrm{EtOCN}-\mathrm{F})_{2}(\mathrm{acac})$ & 0.22 & 21.5 & 2015 & [216] \\
\hline $\operatorname{Ir}(\mathrm{bppo})_{2}(\mathrm{acac})$ & 0.22 & $\ldots$ & 2016 & [217] \\
\hline $\operatorname{Ir}(\mathrm{piq})_{2}(\mathrm{acac})$ & 0.26 & $\ldots$ & 2016 & [210] \\
\hline $\operatorname{Ir}(\mathrm{dmppyph})_{2}(\mathrm{tmd})$ & 0.135 & 38.2 & 2016 & {$[225]$} \\
\hline \multicolumn{5}{|l|}{ Homoleptic complexes } \\
\hline \multirow{4}{*}{ fac-Ir $(\mathrm{ppy})_{3}$} & 0.32 & 18.3 & 2012 & [211] \\
\hline & 0.31 & $\ldots$ & 2014 & [209] \\
\hline & 0.33 & 26.3 & 2014 & [221] \\
\hline & 0.32 & $\ldots$ & 2016 & [210] \\
\hline fac- $\operatorname{Ir}(\mathrm{phq})_{3}$ & 0.30 & 20.9 & 2014 & [219] \\
\hline fac- $\operatorname{Ir}(\text { piq })_{3}$ & 0.22 & $\ldots$ & 2014 & [209] \\
\hline fac-Ir $(\text { chpy })_{3}$ & 0.23 & $\ldots$ & 2014 & [209] \\
\hline fac- $\operatorname{Ir}(\mathrm{tBu}-\mathrm{FCN})_{3}$ & 0.26 & 16.2 & 2015 & [216] \\
\hline $\operatorname{mer}-\operatorname{Ir}(\mathrm{ppy})_{3}$ & 0.33 & $\ldots$ & 2016 & This work \\
\hline
\end{tabular}

octahedral bonding of the organic ligands impart, to a first approximation, a spherical molecular appearance. Such a picture is seen in the well-known fluorescent $\mathrm{Alq}_{3}$, which displays an isotropic orientation of its TDMVs [147]. Hence, the first experimental evidence for the existence of nonisotropic emission of phosphorescent emitters was surprising to the OLED community. When the commonly used red dye iridium(III)bis(2-methyldibenzo-[f,h]quinoxaline)(acetylacetonate) $\left[\operatorname{Ir}(\mathrm{mdq})_{2}(\mathrm{acac})\right]$ is doped into an $N, N^{\prime}$-bis(naphthalen-1-yl)- $N, N^{\prime}$-bis(phenyl)benzidine matrix, a predominant horizontal alignment of its TDMVs results in an anisotropy factor of 0.22 [83]. The apparent molecular alignment has a strong impact on the efficiency analysis of OLEDs using this emitting system [61,64].

Thereafter, the search began for other iridium complexes exhibiting nonisotropic alignment of their TDMVs. As a consequence, several other molecules were found to display behavior similar to $\operatorname{Ir}(\mathrm{mdq})_{2}$ (acac), and the importance to light outcoupling was demonstrated [81,86,87,209-218]. Using the feature of predominantly horizontal alignment of the TDMVs of such Ir complexes subsequently allowed OLED efficiencies for direct 
emission to exceed the value of $30 \%$ [115,219-224]. For a better overview of the extensive number of publications dealing with this special issue, Table II summarizes selected phosphorescent Ir complexes showing deviations from isotropy.

\section{The impact of ancillary ligands}

Shortly before the investigation of the existence of nonisotropic emitter orientation for phosphorescent Ir complexes, an new efficiency record for a green-emitting OLED was published [226]. The extraordinary EQE of $29 \%$ for direct emission was attributed to careful tailoring of work functions and energy levels caused by chlorinating the ITO anode. However, this high value could not be confirmed by optical simulations, as it exceeds the possible efficiency for isotropic light emission. Interestingly, this record OLED used the heteroleptic phosphor $\operatorname{Ir}(\text { ppy })_{2}$ (acac) [bis(2-phenylpyridine)(acetylacetonate)iridium(III)] instead of the more common homoleptic $\operatorname{Ir}(\mathrm{ppy})_{3}$ [fac-tris(2-phenylpyridine)iridium(III)]. The structural difference between those two compounds is that one phenylpyridine was exchanged by an ancillary acetylacetonate ligand [205]. This aliphatic ligand does not change the optical properties of the complex in an appreciable way. However, it does lower the symmetry of the compound from $C_{3}$ for the homoleptic compound to $C_{2}$ for the heteroleptic compound and reduces the number of emitting ligands from three to only two. Since the aforementioned red Ir complex, which showed nonisotropic emitter orientation, was also heteroleptic with an (acac) group as ancillary ligand, it seems likely that both exhibit alignment of their TDMVs, while efficiencies for the homoleptic compound $\left[\operatorname{Ir}(\mathrm{ppy})_{3}\right]$ are only around $20 \%[3,4]$. Consequently, the orientation of $\operatorname{Ir}(\mathrm{ppy})_{2}(\mathrm{acac})$ was determined to be in the same range as for the $\operatorname{Ir}(\mathrm{mdq})_{2}$ (acac) $(\Theta=0.23)$, and the external quantum efficiency of identical devices using either the homoleptic or the heteroleptic green emitter were compared [211,220]. The efficiency of optimized devices from this investigation is shown in Fig. 9. The large impact of the only moderate horizontal alignment of the TDMVs in the $\operatorname{Ir}(\mathrm{ppy})_{2}$ (acac) case is demonstrated, thus, emphasizing the potential for outcoupling improvements if the TDMVs can be perfectly oriented [220].

This first result suggests that heteroleptic Ir complexes, i.e., those exhibiting ancillary ligands, show intrinsic nonisotropic alignment of their emissive TDMVs when deposited by thermal evaporation in high vacuum, even if doped at only a few weight percent in amorphous host materials. Indeed, a search of the literature for such alignment behavior reveals several heteroleptic phosphorescent Ir complexes using $\beta$-diketonate ancillary ligands, i.e., acetylacetonate (acac) or 2,2,6,6-tetramethylheptane-3, 5-diketonate (tmd), whereas only two publications give evidence for alignment of TDMVs in three homoleptic compounds, namely, fac-Ir(piq) ${ }_{3}$ [tris(1-phenylisoquinoline)iridium(III)], fac-Ir(chpy $)_{3}$ (tris[2-(1-cyclo-hexenyl)
pyridine]iridium(III)) [209], and fac- $\operatorname{Ir}(\mathrm{tBu}-\mathrm{FCN})_{3}$ (tris3[4-(tert-butyl)pyridin-2-yl]-2,6-diuorobenzonitrile-iridium (III)) [216]. Hence, it appears that an anisotropic molecular structure that contains a $C_{2}$ symmetry axis induces molecular orientation and preferential alignment of emissive TDMVs in heteroleptic phosphors based on Ir central metal atoms. Furthermore, it is curious that all the anisotropy values for oriented phosphorescent Ir complexes presented to date fall in the same range between 0.18 and 0.24 (see Table II). However, this, in turn, shows that there is still a need to understand and, subsequently, manipulate and increase the alignment of TDMVs to further improve the performance of OLEDs.

\section{Explaining the nonisotropic emitter orientation of iridium complexes}

Although there are numerous examples of nonisotropic emitter orientation for heteroleptic and some homoleptic phosphorescent Ir compounds, the underlying mechanisms for the distinct alignment of the TDMVs is still under

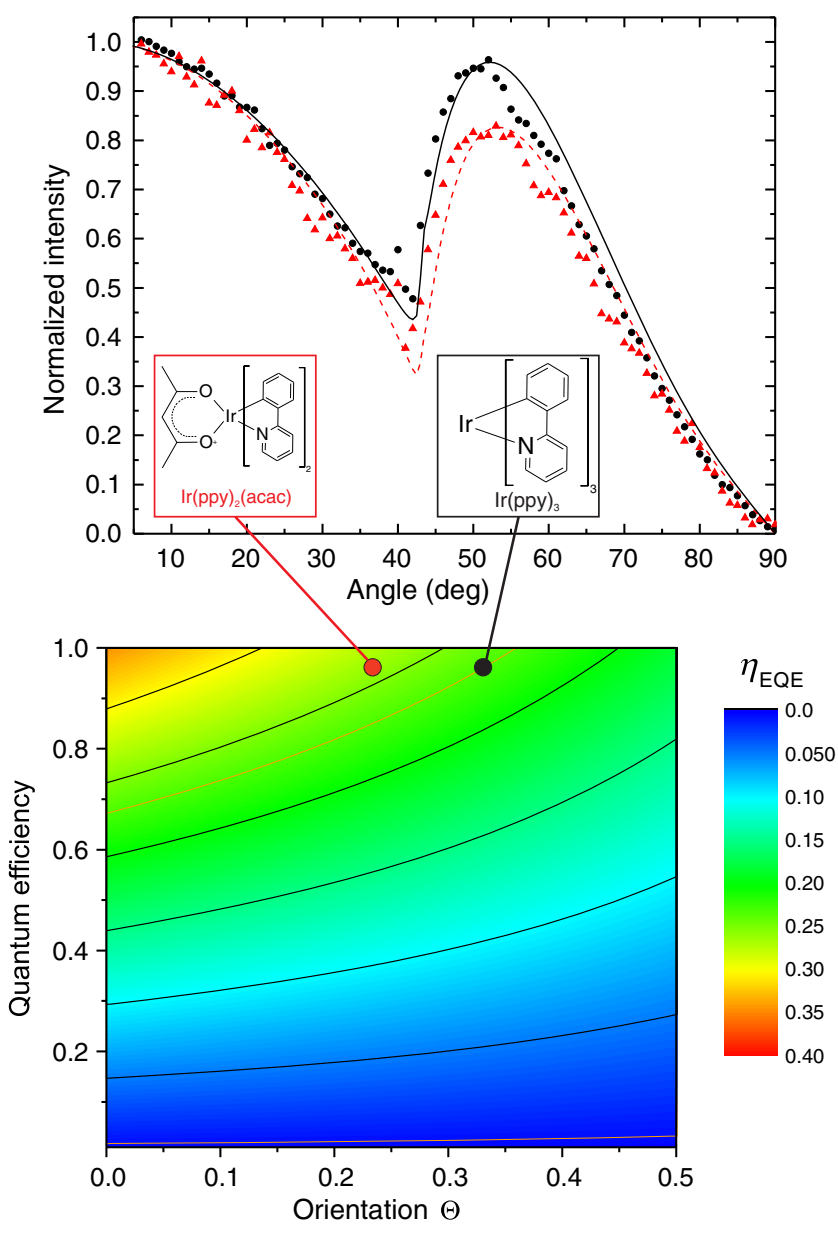

FIG. 9. Experimental results of the EQE of OLEDs exhibiting either the homoleptic $\operatorname{Ir}(\mathrm{ppy})_{3}$ (black dot) or its heteroleptic counterpart $\operatorname{Ir}(\mathrm{ppy})_{2}(\mathrm{acac})$ (red dot) together with orientation measurements and optical simulations as a function of the radiative quantum efficiency $(q)$ and the anisotropy factor $(\Theta)$ for thickness-optimized devices. 
debate. Graf et al. [209] proposed that the permanent dipole moments of the molecules are related to their alignment. They calculated the permanent static dipole of several compounds that show nonisotropic orientation and found most of the aligned complexes exhibit only small permanent dipole moments in the range between 1.5 and 2.0 D. In contrast, $\operatorname{Ir}(\mathrm{ppy})_{3}$ has a large permanent dipole moment of 6.4 D, inducing a strong tendency for agglomeration even for low doping concentrations. Since dipoles tend to align antiparallel to minimize the electrostatic energy of the system, the alignment of the TDMVs is canceled by this process. However, this mechanism cannot explain the observed preferential alignment of TDMVs in $\operatorname{Ir}(\text { piq })_{3}$, as this molecule exhibits a permanent dipole moment of over $5 \mathrm{D}$ that is clearly in the same range as $\operatorname{Ir}(\mathrm{ppy})_{3}$.

Kim et al. [219] and Moon et al. [218] proposed a different physical interaction responsible for the alignment of TDMVs of heteroleptic phosphors, namely, the electrostatic interaction between the emitting molecules and the matrix material. They suggest that the ligands of heteroleptic and homoleptic Ir complexes are attracted by the electrostatic surface potential of the matrix molecules forming so-called supramolecules that align during deposition in a manner favorable to orient the TDMVs. If the host molecules orient horizontal on the underlying surface due to their own anisotropic shape, i.e., long rodlike appearance, the two ligands of the heteroleptic Ir complexes will align in concert with the orientation of the matrix. Consequently, the $C_{2}$ symmetry axis of these molecules, which points from the Ir towards the center of the $\beta$-diketonate ancillary ligand will be oriented perpendicular to the substrate surface, and this, in turn, induces the alignment of the TDMVs. In addition, Moon et al. [218] showed that the orientation of $\operatorname{Ir}(\mathrm{ppy})_{2}(\mathrm{tmd})$ vanishes in UGH-2 due to steric hinderance [218]. Mayr and Brütting [200] investigated the influence of various matrix materials with completely different shapes, e.g., $\mathrm{Alq}_{3}$, Spiro2CBP, TCTA [tris[(4-carbazol-9-yl)-phenyl]amine] and others, on the alignment of different phosphorescent guests, whereas no significant dependence was found.

In order to further investigate these two diverse models of TDMV alignment for phosphors based on Ir central metal atoms, Jurow et al. [217] utilized a new ligand that enabled testing of both proposed alignment models at the same time. They used the benzopyranopyridinone (bppo) ligand and prepared three different $\mathrm{Ir}$ compounds: $\operatorname{Ir}(\mathrm{bppo})_{2}(\mathrm{acac}), \quad \operatorname{Ir}(\mathrm{bppo})_{2}(\mathrm{ppy}), \quad$ and $\operatorname{Ir}(\mathrm{ppy})_{2}$ (bppo) (molecular structures are shown in Fig. 10). The emission of these three complexes originates from the (bppo) ligand, as its triplet energy is lower than either that of (ppy) or (acac). The number of emissive ligands changes from one in $\operatorname{Ir}(\text { ppy })_{2}$ (bppo) to two for the other complexes. All three complexes have permanent dipole moments between 6.2 and $8.4 \mathrm{D}$, even greater than the value of $\operatorname{Ir}(\mathrm{ppy})_{3}$ and present similar electrostatic surface potentials of the emissive ligands. Thus, if the model of Graf et al. were correct, none of the complexes should show anisotropic TDMV distributions once the emitting molecules show agglomeration, which can be achieved by doping at a sufficiently high concentration [for $\operatorname{Ir}(\mathrm{ppy})_{3}$ with a predicted permanent dipole moment of $6.4 \mathrm{D}$, already for a few weight percent]. In contrast, if the model of Kim et al. holds, $\operatorname{Ir}(\mathrm{bppo})_{2}(\mathrm{acac})$ and $\operatorname{Ir}(\mathrm{bppo})_{2}$ (ppy) should show identical orientations, while $\operatorname{Ir}(\mathrm{ppy})_{2}$ (bppo) should exhibit a completely different behavior. In the first case, the two (bppo) ligands should align with the host molecules having their $C_{2}$ (or pseudo- $C_{2}$ ) symmetry axis pointing towards the (acac) or the (ppy) ligand, respectively. This arrangement will orient the $C_{2}$ axes perpendicular to the surface, and, thus, both TDMVs on the respective (bppo) ligands will have similar orientations. In the latter case, the two (ppy) ligands should interact with the host molecules and leave

(a)
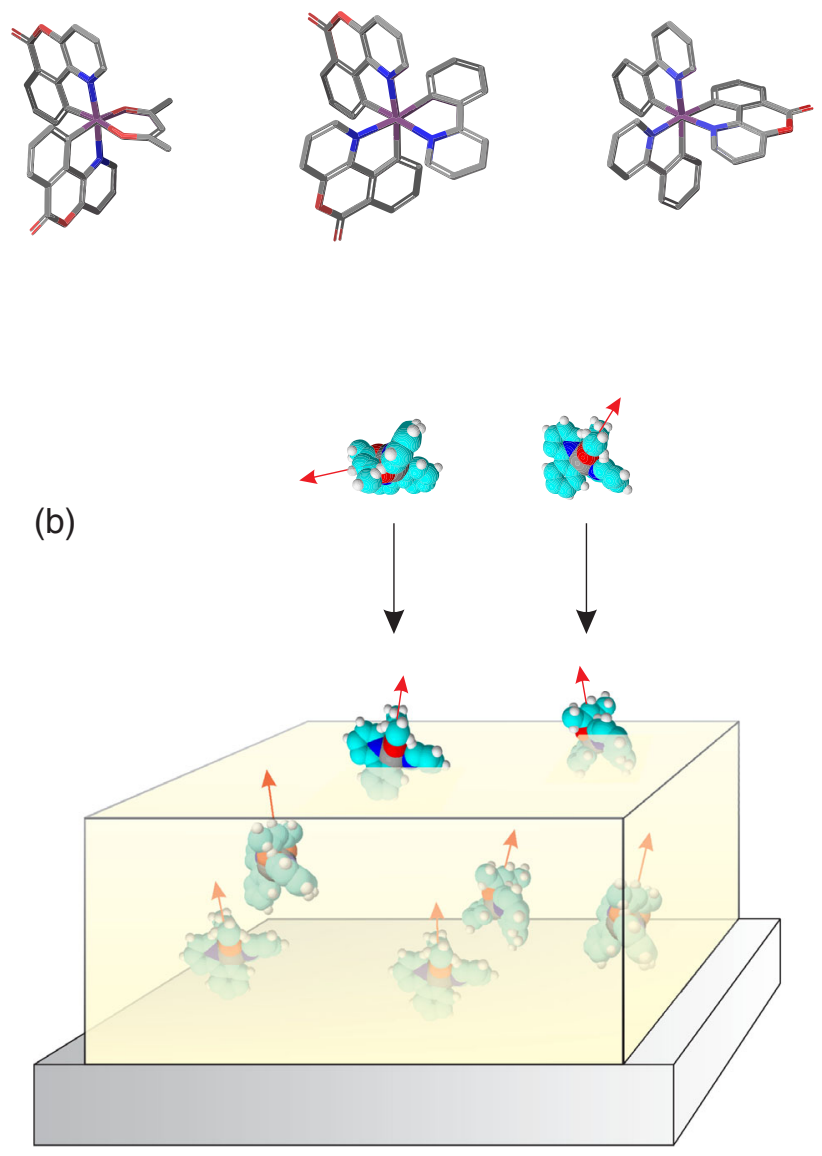

FIG. 10. (a) Molecular structures of (from left to right) $\operatorname{Ir}(\text { bppo })_{2}($ acac $), \operatorname{Ir}(\text { bppo })_{2}$ (ppy), and $\operatorname{Ir}(\text { ppy })_{2}$ (bppo), whereas the direction of the permanent dipole moment is indicated as a green arrow. (b) Supposed orientation model based on interactions of aliphatic and aromatic parts of the emitting molecules with the aromatic host resulting in a perpendicular aligned $C_{2}$ symmetry axis (molecular structures in (a) taken from Ref. [217], (b) adapted from Ref. [210]). 
the (bppo) ligand standing in an upright position and, subsequently, have a pronounced vertical orientation of the TDMV.

However, an investigation into the orientation of all three compounds doped in CBP using the angle-dependent luminescence spectroscopy method shows a predominant horizontal alignment of the TDMVs for $\operatorname{Ir}(\mathrm{bppo})_{2}(\mathrm{acac})$ only, whereas the other compounds show isotropic distributions of their TDMVs. Moreover, these results are not influenced by doping concentration and aggregation of the emitting molecule and, thus, cannot be explained using the orientation model of Graf et al. However, these results provide strong evidence for the $\beta$-diketonate ancillary ligand being solely responsible for the alignment effects and not just simply the anisotropy of the molecule itself.

Consequently, the new model of molecular orientation can explain all the measured anisotropies reported thus far. This model is based on the differences in the chemical nature of the aromatic emissive ligands and the $\beta$-diketonate, which is aliphatic. During the evaporation process, the aromatic ligands of the emitting species try to maximize interaction with the aromatic surface of the already deposited host material (like in the case of solubility of the molecule in different solvents), whereas the aliphatic part remains exposed to the vacuum. Thus, the interface between the already deposited material and the vacuum is responsible for the alignment of the phosphorescent molecules (see Fig. 10). Moreover, this model can also explain the orientation of the three aforementioned homoleptic Ir complexes, as they exhibit anisotropy in their ligands that have more or less aromatic character. This difference induces a vertical orientation of the $C_{3}$ symmetry axis of these molecules, which, in turn, can lead to alignment of the three TDMVs.

Furthermore, Jurow et al. presented a mathematical description of the connection between molecular orientation and measured anisotropy factor values based on the geometrical arrangement of the TDMVs in the molecules. This treatment can be used to design Ir-based phosphors with improved efficiencies, as we discuss in the following section in more detail. Figure 11 shows the outcome of these anisotropy factor simulations in the case of vertical alignment of the $C_{2}$ axis for heteroleptic Ir compounds having one aliphatic ancillary ligand or the $C_{3}$ axis for homoleptic Ir complexes. The curves presume that the respective symmetry axis is perpendicular to the substrate plane, and $\delta$ is the angle between the TDMV and the $\mathrm{Ir}-\mathrm{N}$ bond axis. These simulations show that in both cases an ideal horizontal emitter orientation is possible if the TDMVs are aligned along specific geometrical positions on the molecule.

\section{Design rules for homoleptic iridium complexes}

To further investigate the effects of the TDMV geometry on the emissive dyes, we perform a theoretical study of homoleptic Ir complexes. Various possible structures of

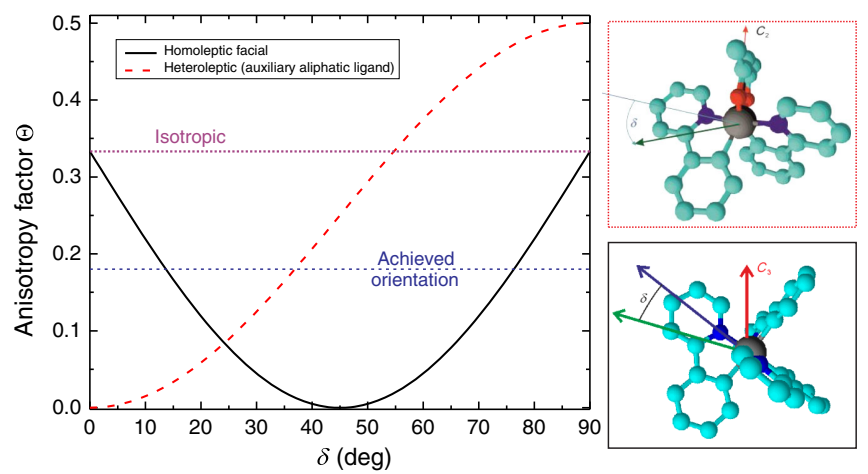

FIG. 11. Simulations of the anisotropy factor of homoleptic and heteroleptic phosphorescent Ir complexes if the $C_{3}$ or the $C_{2}$ axes are aligned perpendicular to the substrate surface, respectively, according to the supposed orientation mechanism. $\delta$ is the angle between the TDMV and the $\mathrm{Ir}-\mathrm{N}$ bond and therewith represents the geometrical orientation of the corresponding TDMV pointing from Ir to the ligand (adapted from Ref. [217]).

homoleptic Ir complexes having different organic ligands, as shown in Fig. 12, yield different orientations of the emissive TDMV with respect to the $\mathrm{Ir}-\mathrm{N}$ bond. From Table III, we see that TDMVs computed using the ZORA approach for the transition between the most emissive triplet $\left(T_{1}\right)$ sublevel and the $S_{0}$ state of $\operatorname{Re}(\mathrm{ppy}) \mathrm{CO}_{4}$ is at an angle $17^{\circ}$ with respect to the Re-N bond. This value is in very good agreement with the experimentally measured TDMV orientation of approximately $18^{\circ}$ [227].

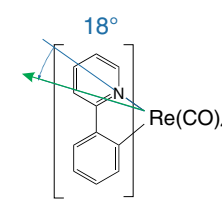

$\mathrm{Re}(\mathrm{ppy}) \mathrm{CO}_{4}$

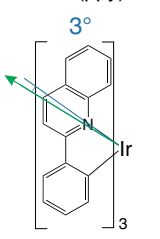

$\operatorname{Ir}(\mathrm{phq})_{3}$ $\operatorname{lr}(1-\text { bzppy })_{3}$

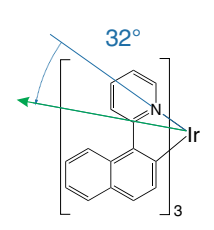

$\operatorname{Ir}(5 \text {-bzppy })_{3}$

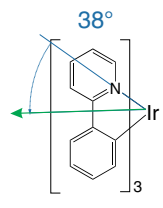

$\operatorname{Ir}(\mathrm{ppy})_{3}$ $11^{\circ}$

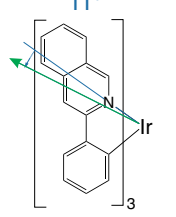

$\operatorname{Ir}(2-\mathrm{bzppy})_{3}$

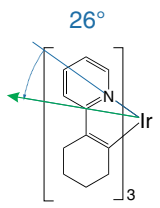

$\operatorname{Ir}(\text { chpy })_{3}$ $43^{\circ}$

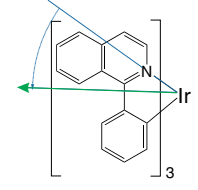

$\operatorname{Ir}(\mathrm{piq})_{3}$ $\operatorname{Ir}(3-\text { bzppy })_{3}$

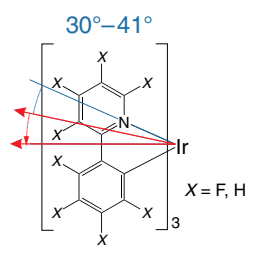

$38^{\circ}$

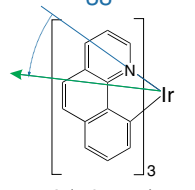

$\operatorname{Ir}(4-\mathrm{bzppy})_{3}$
FIG. 12. Structures and sketched alignments of the TDMVs with respect to the $\mathrm{Ir}-\mathrm{N}$ bond of all the Ir homoleptic complexes for which TDMVs are computed using SOC TDDFT. For details, see Table III. 
TABLE III. The values of $\delta$ calculated using SOC TDDFT for the Ir complexes presented in Fig. 12.

\begin{tabular}{|c|c|c|c|}
\hline Emitter & $\delta(\operatorname{deg})$ & Emitter & $\delta(\operatorname{deg})$ \\
\hline $\operatorname{Re}($ ppy $)(\mathrm{CO})_{4}$ & $17(\sim 18)^{\mathrm{a}}$ & $\operatorname{Ir}(1 \mathrm{~F}-\mathrm{ppy})_{3}$ & 34 \\
\hline $\operatorname{Ir}(\mathrm{ppy})_{3}$ & 38 & $\operatorname{Ir}(2 \mathrm{~F}-\mathrm{ppy})_{3}$ & 30 \\
\hline $\operatorname{Ir}(\operatorname{chpy})_{3}$ & 26 & $\operatorname{Ir}(3 \mathrm{~F}-\mathrm{ppy})_{3}$ & 41 \\
\hline $\operatorname{Ir}(1 \text {-bzppy })_{3} / \operatorname{Ir}(\text { phq })_{3}$ & 3 & $\operatorname{Ir}(4 \mathrm{~F}-\mathrm{ppy})_{3}$ & 34 \\
\hline $\operatorname{Ir}(2 \text {-bzppy })_{3}$ & 11 & $\operatorname{Ir}(7 F-p p y)_{3}$ & 33 \\
\hline $\operatorname{Ir}(3 \text {-bzppy })_{3} / \operatorname{Ir}(\text { piq })_{3}$ & 43 & $\operatorname{Ir}(8 \mathrm{~F}-\mathrm{ppy})_{3}$ & 36 \\
\hline $\operatorname{Ir}(4-b z p p y)_{3}$ & 38 & $\operatorname{Ir}(9 \mathrm{~F}-\mathrm{ppy})_{3}$ & 33 \\
\hline $\operatorname{Ir}(5 \text {-bzppy })_{3}$ & 32 & $\operatorname{Ir}(10 \mathrm{~F}-\text { ppy })_{3}$ & 35 \\
\hline $\operatorname{Ir}(6 \text {-bzppy })_{3}$ & 45 & & \\
\hline $\operatorname{Ir}(7 \text {-bzppy })_{3}$ & 31 & & \\
\hline
\end{tabular}

${ }^{\mathrm{a}}$ Experimentally observed $\delta$ reported in Ref. [227].

Note that this is one of the few phosphorescent systems for which the spatial orientation of the TDMV with respect to the molecular frame has been verified experimentally from measurements on a single crystal. In the absence of any further experimental data, ZORA calculations can be an invaluable tool for studying the alignment of phosphorescent emitters in a host matrix and can complement experimental methods like those reported in this review. We herein demonstrate the utility of such calculations in aiding experimental methods in understanding alignment in a set of closely related facial homoleptic Ir complexes, namely, $\operatorname{Ir}(\text { ppy })_{3}, \operatorname{Ir}(\text { phq })_{3}, \operatorname{Ir}(\text { chpy })_{3}$, and $\operatorname{Ir}(\text { piq })_{3}$. Among these complexes, $\operatorname{Ir}(\text { piq })_{3}$ and $\operatorname{Ir}(\text { chpy })_{3}$ exhibit nonisotropic orientation with anisotropy factors of 0.22 and 0.23 , respectively, while the other two complexes have been reported to show isotropic orientation of the TDMVs. Analysis of the geometry of $\operatorname{Ir}(\mathrm{chpy})_{3}$ shows that when viewed across the $C_{3}$ axis, one-half of the structure is aromatic in nature, whereas the other half is aliphatic as seen in Fig. 13. As we describe in the preceding section, during vapor deposition, $\operatorname{Ir}(\mathrm{chpy})_{3}$ should preferentially orient such that the aromatic end interacts with the aromatic host molecules that have already been deposited, resulting in the $C_{3}$ axis being aligned perpendicular to the substrate. Therefore, a large proportion of the molecules will be aligned with the $C_{3}$ axis vertical, this being the most energetically favorable arrangement. The TDMV associated with the phosphorescent emission of $\operatorname{Ir}(\text { chpy })_{3}$ computed using SOC TDDFT is found to lie in the plane of one of the chpy ligands at an angle $(\delta)$ of $26^{\circ}$ with respect to the $\mathrm{Ir}-\mathrm{N}$ bond. The angle can be compared with results of the anisotropy factor simulations reported in Ref. [217]. For homoleptic complexes with vertical $C_{3}$-axis alignment, the anisotropy factor simulation shown in Fig. 11 predicts nonisotropic net TDMV orientation for the $\delta$ value calculated for $\operatorname{Ir}(\mathrm{chpy})_{3}$. A similar case can be made for the observed nonisotropic TDMV alignment exhibited by $\operatorname{Ir}(\text { piq })_{3}$. Although $\operatorname{Ir}(\text { piq })_{3}$ does not possess aliphatic groups like those seen in $\operatorname{Ir}(\operatorname{chpy})_{3}$, one-half of the
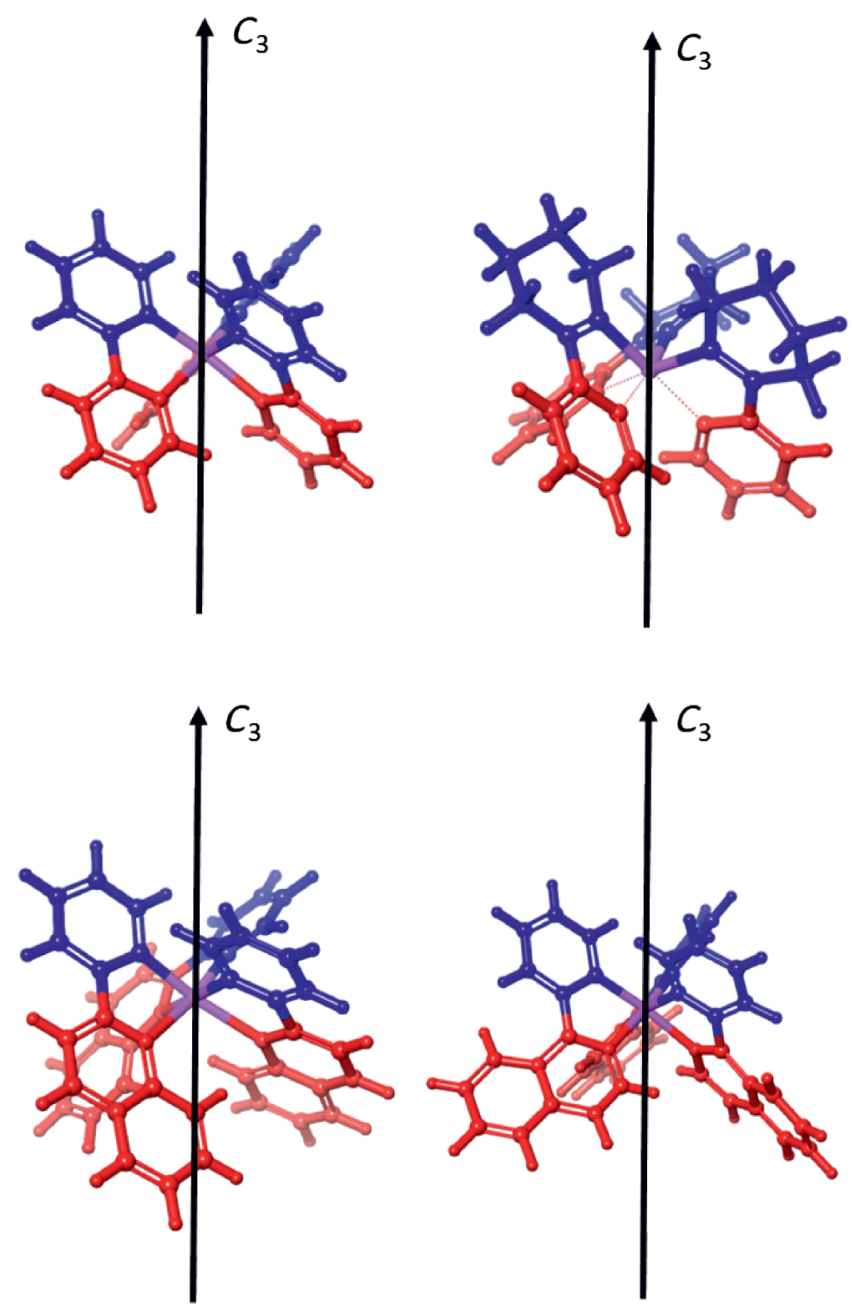

FIG. 13. Orientation of $\operatorname{Ir}(\mathrm{ppy})_{3}, \operatorname{Ir}(\mathrm{chpy})_{3}, \operatorname{Ir}(\mathrm{piq})_{3}$, and $\operatorname{Ir}(\mathrm{phq})_{3}$ (clockwise from upper left) with the $C_{3}$ axis perpendicular to the substrate. (Substrate is assumed to lie perpendicular to the plane of the paper.)

structure is susceptible to increased interaction with an aromatic host, owing to the clustering of the three isoquinoline (two fused aromatic rings) moieties on one end compared to the other end where only three phenyl moieties are exposed. Therefore, the most energetically favorable arrangement will be one in which a majority of the $\operatorname{Ir}(\text { piq })_{3}$ molecules are oriented with the $C_{3}$ axis perpendicular to the substrate. The computed TDMV for $\operatorname{Ir}(\text { piq })_{3}$ lies on one of the piq ligands subtending a $\delta$ angle of $43^{\circ}$. The anisotropy factor simulations (Fig. 11) predict that for this $\delta$ value, $\operatorname{Ir}(\text { piq })_{3}$ will show a much smaller anisotropy factor (i.e., $\Theta \approx 0$ ) in contrast to the observed $\Theta$ of 0.22 .

It should be noted that the anisotropy factor simulation is based on the assumption that all the dopants are aligned with the $C_{3}$ axis lying perpendicular to the substrate. In reality, however, such an idealized picture is highly unlikely, and, instead, a distribution of different possible molecular orientations is expected, however, with a majority of molecules being oriented with their $C_{3}$ axis 
perpendicular or close to perpendicular to the substrate. The anisotropy factor simulations, therefore, represent the maximum achievable value of $\Theta$ for a given value of $\delta$, where any deviation from this maximum value is a measure of disorder in the system. It can also be argued that $\operatorname{Ir}(\text { chpy })_{3}$ has a stronger propensity to orient with its $C_{3}$ axis perpendicular to the substrate compared to $\operatorname{Ir}(\mathrm{piq})_{3}$ on account of the fact that the aromatic aliphatic interface in $\operatorname{Ir}(\text { chpy })_{3}$ offers a much stronger driving force for perpendicular $\left(C_{3}\right.$-axis) alignment than the aromatic-less aromatic interface of $\operatorname{Ir}(\mathrm{piq})_{3}$. Therefore, a larger proportion of $\operatorname{Ir}(\mathrm{chpy})_{3}$ molecules are expected to be aligned perpendicularly against a vacuum-aromatic interface compared to $\operatorname{Ir}(\mathrm{piq})_{3}$. This difference in molecular orientation can explain why $\operatorname{Ir}(\text { piq })_{3}$ and $\operatorname{Ir}(\text { chpy })_{3}$ have near identical values of $\Theta$ in spite of the $16^{\circ}$ difference in their $\delta$ angles.

The structure of $\operatorname{Ir}(\mathrm{phq})_{3}$, like $\operatorname{Ir}(\mathrm{piq})_{3}$, also exposes fused aromatic moieties on one half and phenyl moieties in the opposite half. Therefore, a large proportion of $\operatorname{Ir}(\mathrm{phq})_{3}$ molecules should have their $C_{3}$ axis preferentially aligned perpendicular to the substrate when deposited on the host matrix. However, the TDMV calculated for this complex lies along one of the phq ligands with a $\delta$ angle of $3^{\circ}$ and the anisotropy factor simulations for this value of $\delta$ predict isotropic TDMV alignment, which is what has been reported experimentally. Unlike the other three complexes, $\operatorname{Ir}(\mathrm{ppy})_{3}$ exhibits a relatively isotropic structure, and, hence, the molecules are expected to be randomly oriented in the host matrix. As a consequence, irrespective of the orientation of the TDMV with respect to the molecular frame, $\operatorname{Ir}(\mathrm{ppy})_{3}$ will show an overall isotropic TDMV alignment.

It is now apparent that in addition to the inherent structural asymmetry that determines molecular alignment, an important factor influencing the value of $\Theta$ is the orientation of the TDMV with respect to the molecular frame. It is, therefore, beneficial to understand how chemical modification can alter the direction of the TDMV since this knowledge will enable the rational design of dopants with favorable anisotropy factors. Of the complexes that we discuss above, $\operatorname{Ir}(\mathrm{piq})_{3}$ and $\operatorname{Ir}(\mathrm{phq})_{3}$ are benzannulated derivatives of $\operatorname{Ir}(\mathrm{ppy})_{3}$, with the benzo group attached at the 1 and 3 positions, respectively. These complexes have distinctly different $\delta$ values. We, therefore, embark upon a systematic study of how benzo groups will affect the direction of the TDMV when added to different positions on the parent $\operatorname{Ir}(\mathrm{ppy})_{3}$ complex. The $\delta$ values computed for the homoleptic Ir complexes based on all possible benzannulated derivatives of the ppy ligand are tabulated in Table III; a 2D illustration of the TDMVs of all the complexes is shown in Fig. 12 for comparison. Based on the calculated TDMVs, $\operatorname{Ir}(\text { piq })_{3}$ and $\operatorname{Ir}(6 \text {-bzppy })_{3}$ can be expected to show lower $\Theta$ values compared to the other homoleptic complexes with perpendicularly aligned molecular $C_{3}$ axes. It should be noted that despite having a favorable $\delta$ angle of $45^{\circ}, \operatorname{Ir}(4 \text {-bzppy })_{3}$ is unlikely to

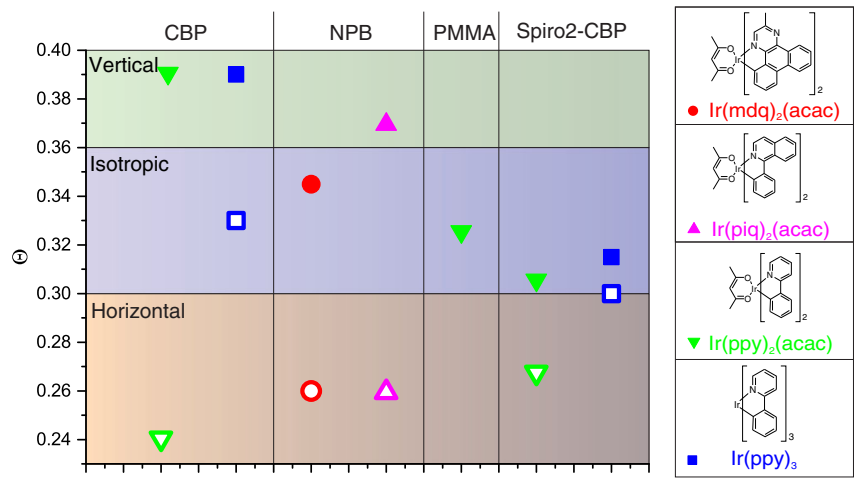

FIG. 14. Comparison of phosphorescent guest-host systems prepared from solution and thermal evaporation (adapted from Ref. [210]).

exhibit low anisotropy factors owing to the lack of structural asymmetry as in the case of $\operatorname{Ir}(\mathrm{ppy})_{3}$.

We also explore the influence of fluorine substitutions at different positions of the ppy ligand on the direction of the TDMV. We find that $\operatorname{Ir}(3 \mathrm{~F}-\mathrm{ppy})_{3}$ is expected to show the lowest value of $\Theta$ among all the fluoro-substituted derivatives (Table III).

Future work in our group will focus on using SOC TDDFT calculations to predict TDMV orientation across a large family of Ir and Pt complexes and corroborate the results with experimental data whenever possible. This information will ultimately lead to a greater understanding of the factors that influence alignment in such systems, paving the way for rational design of emitters with low $\Theta$ values.

\section{Implications for device fabrication}

Besides the implications for the future design of phosphorescent Ir complexes, the presented orientation model also has consequences on the alignment of molecules if fabrication techniques other than thermal evaporation in vacuum are used. The two most promising methods for fast low-cost, roll-to-roll fabrication of OLED are solutionbased techniques and organic vapor phase deposition where the latter technique profits from fabrication conditions under low vacuum.

However, OLEDs prepared from solution will not have a solid-vacuum interface where orientation can take place during fabrication. Thus, preferential horizontal alignment of the TDMVs of phosphorescent Ir complexes should not be favored. In order to test this hypothesis, Lampe et al. investigated the orientation of four different Ir complexes, three heteroleptic showing horizontal alignment of their TDMVs when prepared by thermal evaporation and the homoleptic $\operatorname{Ir}(\text { ppy })_{3}$ known for its isotropic emitter orientation, in four different host materials. Differences were compared between films fabricated by spin coating from solution versus thermal evaporation in vacuum [210]. The results depicted in Fig. 14 demonstrate that predominantly 
horizontal alignment of the TDMVs of these phosphors is possible only if prepared by thermal evaporation. All samples prepared by spin casting exhibit isotropic distribution of the TDMVs, in agreement with the predictions of the orientation model based on the interaction of molecules at the interface between the growing film and vacuum. Moreover, it seems that for hosts with low glass transition temperature, the samples tend to undergo fast crystallization after the spin-coating process, resulting in slightly vertical emitter orientation. However, this effect vanishes for high- $T_{g}$ materials like Spiro-2CBP, where perfect isotropic distribution of the TDMVs is achieved. It is worth noting here that host materials with high glass transition temperatures often form birefringent films, which has to be properly taken into account for accurate optical simulations.

The same authors further investigated the emitter orientation of Ir-based phosphors if the films were prepared by organic vapor phase deposition (OVPD) [228]. It was demonstrated that films of phosphorescent dopants in amorphous organic host materials can be grown by OVPD with identical dopant orientation metrics as films prepared by thermal evaporation in high vacuum. These observations show that OVPD should be further investigated for use in the fabrication of highly efficient OLEDs. Critically, the impact of substrate temperature should not be overlooked as a controlling factor of the organization of doped organic films and should be a topic of future research [186].

\section{B. Promising concepts: Phosphorescence from platinum complexes}

In the previous sections, we talk about emitter orientation for phosphorescent organometallic molecules based on Ir as a central metal atom; however, a material class less considered in recent years has just had a stunning comeback [229]. Platinum complexes were promising materials for OLED application in the beginning of the phosphorescence era. However, they received less interest relative to their Ir-based counterparts as their performance in OLEDs suffers from long excited-state lifetimes as well as narrow emission, the latter effect being good for display applications but unfavorable for general lighting.

Nevertheless, due to their square-planar coordination geometry and flat disklike molecular shape, Pt complexes are promising candidates for nonisotropic orientation, as their TDMVs typically lie in the molecular plane. Surprisingly, few publications deal with this feature, as EQE values reach only $20 \%$ due to moderate alignment of the involved emissive TDMVs [230,231].

The orientation factor of the common phosphorescent complex platinum(II) octaethylporphyrin (PtOEP) incorporated into disk-shaped matrix materials such as 4,6-bis[3,5di(pyridine-3-yl)phenyl]-2-methylpyrimidine (B3PYMPM) was investigated by Kim and co-workers [232]. The
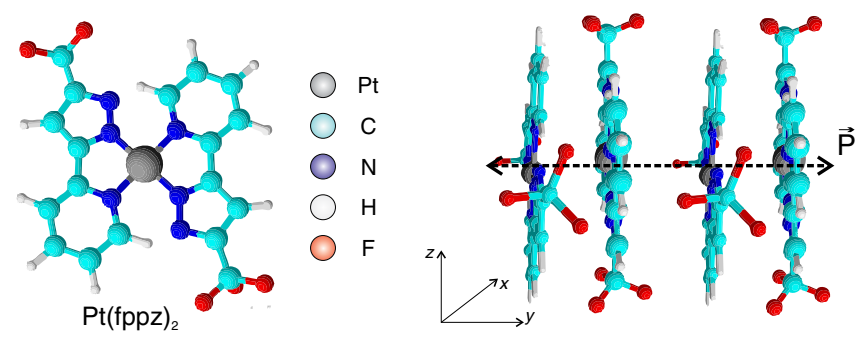

FIG. 15. Molecular structures of the fluorinated platinum complex $\mathrm{Pt}(\mathrm{fppz})_{2}$ showing high tendency of forming crystals (see side view) in evaporated neat films. Here, the transition dipole moment vector is assumed to be aligned between the platinum atoms of two adjacent molecules as depicted in the right sketch. This complex can achieve extraordinary high external quantum-efficiency values up to $39 \%$ (molecular structures taken from Ref. [229]).

resultant dye orientation in such guest-host systems can be controlled via the anisotropy of the host. This alignment behavior with the guest and host molecules being parallel to each other is probably induced by $\pi-\pi$ interactions due to the planar conjugated structure. However this concept has been proven only for PtOEP, and further studies are required to verify its validity for different Pt complexes.

Another promising concept that dramatically increased both the EQE and horizontal emitter orientation was recently presented by Kim et al. [229]. They synthesized three fluorinated platinum complexes Pt(f2bipz) (bpy) (Pt(II)[5,5-di(triuoromethyl)-3,3-bipyrazolate](2,2bipyridine)), $\mathrm{Pt}(\mathrm{fppz})(\mathrm{pic})$ (Pt(II)[3-(triuoromethyl)-5-(2pyridyl)pyrazolate] (picolinate)), and $\mathrm{Pt}(\mathrm{fppz})_{2}[\mathrm{Pt}(\mathrm{II})$ bis(3-(triuoromethyl)-5-(2-pyridyl)-pyrazolate)], which form crystalline films upon evaporation but still show high luminescent quantum efficiencies over $90 \%$ even in such neat layers. Because of the laminar packing of these disklike molecules, they are perfectly aligned and show very low anisotropy factors (see Fig. 15). Indeed, angledependent luminescence spectroscopy investigations give $\Theta$ values of $0.7,0.1$, and 0.14 for $\mathrm{Pt}(\mathrm{fppz})_{2}, \operatorname{Pt}(\mathrm{f} 2 \mathrm{bipz})$ (bpy), and $\mathrm{Pt}(\mathrm{fppz})(\mathrm{pic})$, respectively. Consequently, the authors fabricated OLEDs exhibiting a neat crystalline layer of the these platinum complexes. The devices achieved a new external quantum efficiency (direct emission) record of $39 \%$ for an OLED comprising the $\mathrm{Pt}(\mathrm{fppz})_{2}$ emission layer, illustrating the potential of using phosphorescence from platinum complexes for future OLED applications. However, it is worth noting that emission from these platinum complexes does not originate from a classical triplet MLCT state but instead has metal-metal-toligand charge-transfer character due to dimer formation upon crystalline growth, as we show in Fig. 15. This, in turn, means that the long molecular axis of these platinum complexes is orientated perpendicular to the main TDMV in the crystalline phase. Thus, for this approach, the 
favorable molecular orientation for increasing light outcoupling in OLEDs is not horizontal but vertical to the substrate plane.

\section{SUMMARY}

Emitter orientation has already been recognized as a decisive parameter for light outcoupling and, thus, efficiency improvement in OLEDs. In this article, we review the current understanding of this phenomenon and its relevance for device application. As we describe in the preceding sections, there are different driving forces depending on the type of emitter material and, related to that, different design rules for materials and fabrication protocols for devices in order to achieve a higher degree of horizontal alignment of the transition dipole moment vectors. Still more work is needed to extend the knowledge base and improve the mechanistic understanding. However, we anticipate that this phenomenon can make a significant contribution toward bringing OLED efficiency further up and reaching values in the $40 \%$ range.

\section{ACKNOWLEDGMENTS}

T. D. S., T. L., and W. B. acknowledge funding by Bavaria California Technology Center, by the German Ministry for Education and Research (Project No. 13N13664), as well as by Deutsche Forschungsgemeinschaft (Project No. Br 1728/ 20-1). D. S. M. R., P. I. D., and M. E. T. thank the Universal Display Corporation for financial support, Schrödinger Inc. for access to the MATERIALS SUITE software package, and Dr. Mathew Halls of Schrödinger for helpful discussions.

[1] C. W. Tang and S. A. VanSlyke, Organic electroluminescent diodes, Appl. Phys. Lett. 51, 913 (1987).

[2] M. A. Baldo, D. F. O'Brien, Y. You, A. Shoustikov, S. Sibley, M. E. Thompson, and S. R. Forrest, Highly efficient phosphorescent emission from organic electroluminescent devices, Nature (London) 395, 151 (1998).

[3] M. A. Baldo, S. Lamansky, P. E. Burrows, M. E. Thompson, and S. R. Forrest, Very high-efficiency green organic light-emitting devices based on electrophosphorescence, Appl. Phys. Lett. 75, 4 (1999).

[4] C. Adachi, M. A. Baldo, M. E. Thompson, and S. R. Forrest, Nearly $100 \%$ internal phosphorescence efficiency in an organic light-emitting device, J. Appl. Phys. 90, 5048 (2001).

[5] B. Tong, Q. Mei, S. Wang, Y. Fang, Y. Meng, and B. Wang, Nearly $100 \%$ internal phosphorescence efficiency in a polymer light-emitting diode using a new iridium complex phosphor, J. Mater. Chem. 18, 1636 (2008).

[6] S. R. Forrest, The path to ubiquitous and low-cost organic electronic appliances on plastic, Nature (London) 428, 911 (2004).

[7] S. Reineke, F. Lindner, G. Schwartz, N. Seidler, K. Walzer, B. Lussem, and K. Leo, White organic light-emitting diodes with fluorescent tube efficiency, Nature (London) 459, 234 (2009).

[8] T. Tsutsui, E. Aminaka, C. P. Lin, and D. U. Kim, Extended molecular design concept of molecular materials for electroluminescence: Sublimed-dye films, molecularly doped polymers and polymers with chromophores, Phil. Trans. R. Soc. A 355, 801 (1997).

[9] M. Pfeiffer, S. R. Forrest, K. Leo, and M. E. Thompson, Electrophosphorescent $p$ - $i$ - $n$ organic light-emitting devices for very-high-efficiency flat-panel displays, Adv. Mater. 14, 1633 (2002).

[10] M. Pfeiffer, K. Leo, X. Zhou, J. S. Huang, M. Hofmann, A. Werner, and J. Blochwitz-Nimoth, Doped organic semiconductors: Physics and application in light emitting diodes, Org. Electron. 4, 89 (2003).

[11] V. I. Adamovich, S. R. Cordero, P. I. Djurovich, A. Tamayo, M. E. Thompson, B. W. D'Andrade, and S. R. Forrest, New charge-carrier blocking materials for high efficiency OLEDs, Org. Electron. 4, 77 (2003).

[12] G. He, O. Schneider, D. Qin, X. Zhou, M. Pfeiffer, and K. Leo, Very high-efficiency and low voltage phosphorescent organic light-emitting diodes based on a $p-i-n$ junction, $\mathrm{J}$. Appl. Phys. 95, 5773 (2004).

[13] G. He, M. Pfeiffer, K. Leo, M. Hofmann, J. Birnstock, R. Pudzich, and J. Salbeck, High-efficiency and low-voltage $p-i$ - $n$ electrophosphorescent organic light-emitting diodes with double-emission layers, Appl. Phys. Lett. 85, 3911 (2004).

[14] M. A. Baldo, D. F. O'Brien, M. E. Thompson, and S. R. Forrest, Excitonic singlet-triplet ratio in a semiconducting organic thin film, Phys. Rev. B 60, 14422 (1999).

[15] R. H. Friend, R.W. Gymer, A. B. Holmes, J. H. Burroughes, R. N. Marks, C. Taliani, D. D. C. Bradley, D. A. Dos Santos, J. L. Bredas, M. Logdlund, and W. R. Salaneck, Electroluminescence in conjugated polymers, Nature (London) 397, 121 (1999).

[16] M. Segal, M. A. Baldo, R. J. Holmes, S. R. Forrest, and Z. G. Soos, Excitonic singlet-triplet ratios in molecular and polymeric organic materials, Phys. Rev. B 68, 075211 (2003).

[17] Z. Shuai, D. Beljonne, R. J. Silbey, and J. L. Brédas, Singlet and Triplet Exciton Formation Rates in Conjugated Polymer Light-Emitting Diodes, Phys. Rev. Lett. 84, 131 (2000).

[18] M. Wohlgenannt, Polarons in pi-conjugated semiconductors: Absorption spectroscopy and spin-dependent recombination, Phys. Status Solidi (a) 201, 1188 (2004).

[19] T. Tsutsui, M.-J. Yang, M. Yahiro, K. Nakamura, T. Watanabe, T. Tsuji, Y. Fukuda, T. Wakimoto, and S. Miyaguchi, High quantum efficiency in organic lightemitting devices with iridium-complex as a triplet emissive center, Jpn. J. Appl. Phys. 38, L1502 (1999).

[20] D. F. O'Brien, M. A. Baldo, M. E. Thompson, and S. R. Forrest, Improved energy transfer in electrophosphorescent devices, Appl. Phys. Lett. 74, 442 (1999).

[21] A. M. Baldo, M. E. Thompson, and S. R. Forrest, Phosphorescent materials for application to organic light emitting devices, Pure Appl. Chem. 71, 2095 (1999).

[22] R. C. Kwong, S. Sibley, T. Dubovoy, M. Baldo, S. R. Forrest, and M.E. Thompson, Efficient, saturated red 
organic light emitting devices based on phosphorescent platinum(ii) porphyrins, Chem. Mater. 11, 3709 (1999).

[23] C.-L. Lee, K. B. Lee, and J.-J. Kim, Polymer phosphorescent light-emitting devices doped with tris(2-phenylpyridine) iridium as a triplet emitter, Appl. Phys. Lett. 77, 2280 (2000).

[24] J. S. Wilson, A. S. Dhoot, A. J. A. B. Seeley, M. S. Khan, A. Köhler, and R.H. Friend, Spin-dependent exciton formation in $\pi$-conjugated compounds, Nature (London) 413, 828 (2001).

[25] Y. Sun, N. C. Giebink, H. Kanno, B. Ma, M. E. Thompson, and S.R. Forrest, Management of singlet and triplet excitons for efficient white organic light-emitting devices, Nature (London) 440, 908 (2006).

[26] H. Yersin, A. F. Rausch, R. Czerwieniec, T. Hofbeck, and T. Fischer, The triplet state of organo-transition metal compounds. Triplet harvesting and singlet harvesting for efficient OLEDs, Coord. Chem. Rev. 255, 2622 (2011).

[27] A. Jablonski, Über den Mechanismus der Photolumineszenz von Farbstoffphosphoren, Z. Phys. 94, 38 (1935).

[28] G. N. Lewis, D. Lipkin, and T. T. Magel, Reversible photochemical processes in rigid media. A study of the phosphorescent state, J. Am. Chem. Soc. 63, 3005 (1941).

[29] C. A. Parker and C. G. Hatchard, Triplet-singlet emission in fluid solution, J. Phys. Chem. 66, 2506 (1962).

[30] C. A. Parker, Sensitized $p$-type delayed fluorescence, Proc. R. Soc. A 276, 125 (1963).

[31] C. A. Parker and T. A. Joyce, Delayed fluorescence and some properties of the chlorophyll triplets, Photochem. Photobiol. 6, 395 (1967).

[32] R. E. Brown, L. A. Singer, and J. H. Parks, Prompt and delayed fluorescence from benzophenone, Chem. Phys. Lett. 14, 193 (1972).

[33] K. Goushi, K. Yoshida, K. Sato, and C. Adachi, Organic light-emitting diodes employing efficient reverse intersystem crossing for triplet-to-singlet state conversion, Nat. Photonics 6, 253 (2012).

[34] H. Uoyama, K. Goushi, K. Shizu, H. Nomura, and C. Adachi, Highly efficient organic light-emitting diodes from delayed fluorescence, Nature (London) 492, 234 (2012).

[35] J. W. Sun, J.-H. Lee, C.-K. Moon, K.-H. Kim, H. Shin, and J.-J. Kim, A fluorescent organic light-emitting diode with $30 \%$ external quantum efficiency, Adv. Mater. 26, 5684 (2014).

[36] F. B. Dias, K. N. Bourdakos, V. Jankus, K. C. Moss, K. T. Kamtekar, V. Bhalla, J. Santos, M. R. Bryce, and A. P. Monkman, Triplet harvesting with $100 \%$ efficiency by way of thermally activated delayed fluorescence in charge transfer OLED emitters, Adv. Mater. 25, 3707 (2013).

[37] Q. Zhang, B. Li, Sh. Huang, H. Nomura, H. Tanaka, and C. Adachi, Efficient blue organic light-emitting diodes employing thermally activated delayed fluorescence, Nat. Photonics 8, 326 (2014).

[38] Y. Im and J. Y. Lee, Above 20\% external quantum efficiency in thermally activated delayed fluorescence device using furodipyridine-type host materials, Chem. Mater. 26, 1413 (2014).

[39] H. Sternlicht, G. C. Nieman, and G. W. Robinson, Triplettriplet annihilation and delayed fluorescence in molecular aggregates, J. Chem. Phys. 38, 1326 (1963).
[40] D. Y. Kondakov, T. D. Pawlik, T. K. Hatwar, and J. P. Spindler, Triplet annihilation exceeding spin statistical limit in highly efficient fluorescent organic light-emitting diodes, J. Appl. Phys. 106, 124510 (2009).

[41] Y. Luo and H. Aziz, Correlation between triplet-triplet annihilation and electroluminescence efficiency in doped fluorescent organic light-emitting devices, Adv. Funct. Mater. 20, 1285 (2010).

[42] D. Yokoyama, Y. Park, B. Kim, S. Kim, Y.-J. Pu, J. Kido, and J. Park, Dual efficiency enhancement by delayed fluorescence and dipole orientation in high-efficiency fluorescent organic light-emitting diodes, Appl. Phys. Lett. 99, 123303 (2011).

[43] Y.-J. Pu, G. Nakata, F. Satoh, H. Sasabe, D. Yokoyama, and J. Kido, Optimizing the charge balance of fluorescent organic light-emitting devices to achieve high external quantum efficiency beyond the conventional upper limit, Adv. Mater. 24, 1765 (2012).

[44] C.-J. Chiang, A. Kimyonok, M. K. Etherington, G. C. Griffiths, V. Jankus, F. Turksoy, and A. P. Monkman, Ultrahigh efficiency fluorescent single and bi-layer organic light emitting diodes: The key role of triplet fusion, Adv. Funct. Mater. 23, 739 (2013).

[45] V. Jankus, C.-J. Chiang, F. Dias, and A. P. Monkman, Deep blue exciplex organic light-emitting diodes with enhanced efficiency; $p$-type or $e$-type triplet conversion to singlet excitons?, Adv. Mater. 25, 1455 (2013).

[46] C. Mayr, T. D. Schmidt, and W. Brütting, High-efficiency fluorescent organic light-emitting diodes enabled by triplet-triplet annihilation and horizontal emitter orientation, Appl. Phys. Lett. 105, 183304 (2014).

[47] T. Suzuki, Y. Nonaka, T. Watabe, H. Nakashima, S. Seo, S. Shitagaki, and S. Yamazaki, Highly efficient long-life blue fluorescent organic light-emitting diode exhibiting triplettriplet annihilation effects enhanced by a novel holetransporting material, Jpn. J. Appl. Phys. 53, 052102 (2014).

[48] H. Becker, S. E. Burns, and R. H. Friend, Effect of metal films on the photoluminescence and electroluminescence of conjugated polymers, Phys. Rev. B 56, 1893 (1997).

[49] R. R. Chance, A. Prock, and R. Silbey, Lifetime of an emitting molecule near a partially reflecting surface, J. Chem. Phys. 60, 2744 (1974).

[50] R. R. Chance, A. Prock, and R. Silbey, Advances in Chemical Physics (John Wiley \& Sons, Inc., New York, 2007), pp. 1-65.

[51] J. A. E. Wasey and W. L. Barnes, Efficiency of spontaneous emission from planar microcavities, J. Mod. Opt. 47, 725 (2000).

[52] L. H. Smith, J. A. E. Wasey, I. D. W. Samuel, and W. L. Barnes, Light out-coupling efficiencies of organic lightemitting diode structures and the effect of photoluminescence quantum yield, Adv. Funct. Mater. 15, 1839 (2005).

[53] J. A. E. Wasey, A. Safonov, I. D. W. Samuel, and W. L. Barnes, Efficiency of radiative emission from thin films of a light-emitting conjugated polymer, Phys. Rev. B 64, 205201 (2001).

[54] K. H. Drexhage, Influence of a dielectric interface on fluorescence decay time, J. Lumin. 1, 693 (1970).

[55] K. Drexhage, Interaction of light with monomolecular dye layers, Prog. Opt. 12, 163 (1974). 
[56] K. A. Neyts, Simulation of light emission from thin-film microcavities, J. Opt. Soc. Am. A 15, 962 (1998).

[57] X.-W. Chen, W. C. H. Choy, C. J. Liang, P. K. A. Wai, and $\mathrm{S}$. He, Modifications of the exciton lifetime and internal quantum efficiency for organic light-emitting devices with a weak/strong microcavity, Appl. Phys. Lett. 91, 221112 (2007).

[58] S. Nowy, B. C. Krummacher, J. Frischeisen, N. A. Reinke, and W. Brütting, Light extraction and optical loss mechanisms in organic light-emitting diodes: Influence of the emitter quantum efficiency, J. Appl. Phys. 104, 123109 (2008).

[59] R. Meerheim, M. Furno, S. Hofmann, B. Lüssem, and K. Leo, Quantification of energy loss mechanisms in organic light-emitting diodes, Appl. Phys. Lett. 97, 253305 (2010).

[60] D. S. Setz, T. D. Schmidt, M. Flämmich, S. Nowy, J. Frischeisen, B. C. Krummacher, T. Dobbertin, K. Heuser, D. Michaelis, N. Danz, W. Brütting, and A. Winnacker, Comprehensive efficiency analysis of organic lightemitting devices, J. Photon. Energy 1, 011006 (2011).

[61] T. D. Schmidt, D. S. Setz, M. Flämmich, J. Frischeisen, D. Michaelis, B. C. Krummacher, N. Danz, and W. Brütting, Evidence for non-isotropic emitter orientation in a red phosphorescent organic light-emitting diode and its implications for determining the emitter's radiative quantum efficiency, Appl. Phys. Lett. 99, 163302 (2011).

[62] M. Furno, R. Meerheim, S. Hofmann, B. Lüssem, and K. Leo, Efficiency and rate of spontaneous emission in organic electroluminescent devices, Phys. Rev. B 85, 115205 (2012).

[63] E. M. Purcell, Spontaneous emission probabilities at radio frequencies, Phys. Rev. 69, 681 (1946).

[64] T. D. Schmidt, M. Flämmich, B. J. Scholz, D. Michaelis, C. Mayr, N. Danz, and W. Brütting, Non-isotropic emitter orientation and its implications for efficiency analysis of organic light-emitting diodes, Proc. SPIE Int. Soc. Opt. Eng. 8435, 843513 (2012).

[65] N. C. Giebink, B. W. D. Andrade, M. S. Weaver, P. B. Mackenzie, J. J. Brown, M. E. Thompson, and S. R. Forrest, Intrinsic luminance loss in phosphorescent small-molecule organic light emitting devices due to bimolecular annihilation reactions, J. Appl. Phys. 103, 044509 (2008).

[66] N. C. Giebink and S. R. Forrest, Quantum efficiency rolloff at high brightness in fluorescent and phosphorescent organic light emitting diodes, Phys. Rev. B 77, 235215 (2008).

[67] D. Song, S. Zhao, and H. Aziz, Modification of exciton lifetime by the metal cathode in phosphorescent OLEDs, and implications on device efficiency and efficiency rolloff behavior, Adv. Funct. Mater. 21, 2311 (2011).

[68] W. Staroske, M. Pfeiffer, K. Leo, and M. Hoffmann, Single-Step Triplet-Triplet Annihilation: An Intrinsic Limit for the High Brightness Efficiency of Phosphorescent Organic Light Emitting Diodes, Phys. Rev. Lett. 98, 197402 (2007).

[69] M. A. Baldo, C. Adachi, and S. R. Forrest, Transient analysis of organic electrophosphorescence. Transient analysis of triplet-triplet annihilation, Phys. Rev. B 62, 10967 (2000).
[70] S. Reineke, K. Walzer, and K. Leo, Triplet-exciton quenching in organic phosphorescent light-emitting diodes with Ir-based emitters, Phys. Rev. B 75, 125328 (2007).

[71] D. Song, S. Zhao, Y. Luo, and H. Aziz, Causes of efficiency roll-off in phosphorescent organic light emitting devices: Triplet-triplet annihilation versus triplet-polaron quenching, Appl. Phys. Lett. 97, 243304 (2010).

[72] S. M. King, M. Cass, M. Pintani, C. Coward, F. B. Dias, A. P. Monkman, and M. Roberts, The contribution of triplet-triplet annihilation to the lifetime and efficiency of fluorescent polymer organic light emitting diodes, J. Appl. Phys. 109, 074502 (2011).

[73] C. Murawski, K. Leo, and M. C. Gather, Efficiency roll-off in organic light-emitting diodes, Adv. Mater. 25, 6801 (2013).

[74] C. Murawski, P. Liehm, K. Leo, and M. C. Gather, Influence of cavity thickness and emitter orientation on the efficiency roll-off of phosphorescent organic lightemitting diodes, Adv. Funct. Mater. 24, 1117 (2014).

[75] H. van Eersel, P. A. Bobbert, R. A. J. Janssen, and R. Coehoorn, Monte Carlo study of efficiency roll-off of phosphorescent organic light-emitting diodes: Evidence for dominant role of triplet-polaron quenching, Appl. Phys. Lett. 105, 143303 (2014).

[76] S. Wehrmeister, L. Jäger, T. Wehlus, A. F. Rausch, T. C. G. Reusch, T.D. Schmidt, and W. Brütting, Combined Electrical and Optical Analysis of the Efficiency RollOff in Phosphorescent Organic Light-Emitting Diodes, Phys. Rev. Applied 3, 024008 (2015).

[77] R. Coehoorn, H. van Eersel, P. Bobbert, and R. Janssen, Kinetic Monte Carlo study of the sensitivity of OLED efficiency and lifetime to materials parameters, Adv. Funct. Mater. 25, 2024 (2015).

[78] W. L. Barnes, Fluorescence near interfaces: The role of photonic mode density, J. Mod. Opt. 45, 661 (1998).

[79] N. C. Greenham, R. H. Friend, and D. D. C. Bradley, Angular dependence of the emission from a conjugated polymer light-emitting diode: Implications for efficiency calculations, Adv. Mater. 6, 491 (1994).

[80] S. Nowy, J. Frischeisen, and W. Brütting, Simulation based optimization of light-outcoupling in organic light-emitting diodes, Proc. SPIE Int. Soc. Opt. Eng. 7415, 74151C (2009).

[81] T. D. Schmidt, B. J. Scholz, C. Mayr, and W. Brütting, Efficiency analysis of organic light-emitting diodes based on optical simulations, IEEE J. Sel. Top. Quantum Electron. 19, 1 (2013).

[82] J. Frischeisen, D. Yokoyama, A. Endo, C. Adachi, and W. Brütting, Increased light outcoupling efficiency in dyedoped small molecule organic light-emitting diodes with horizontally oriented emitters, Org. Electron. 12, 809 (2011).

[83] M. Flämmich, J. Frischeisen, D. S. Setz, D. Michaelis, B. C. Krummacher, T. D. Schmidt, W. Brütting, and N. Danz, Oriented phosphorescent emitters boost OLED efficiency, Org. Electron. 12, 1663 (2011).

[84] J. Frischeisen, B. J. Scholz, B. J. Arndt, T. D. Schmidt, R. Gehlhaar, C. Adachi, and W. Brütting, Strategies for light extraction from surface plasmons in organic light-emitting diodes, J. Photon. Energy 1, 011004 (2011). 
[85] B. J. Scholz, J. Frischeisen, A. Jaeger, D. S. Setz, T. C. G. Reusch, and W. Brütting, Extraction of surface plasmons in organic light-emitting diodes via high-index coupling, Opt. Express 20, A205 (2012).

[86] W. Brütting, J. Frischeisen, T. D. Schmidt, B. J. Scholz, and C. Mayr, Device efficiency of organic light-emitting diodes: Progress by improved light outcoupling, Phys. Status Solidi (a) 210, 44 (2013).

[87] M. C. Gather and S. Reineke, Recent advances in light outcoupling from white organic light-emitting diodes, J. Photon. Energy 5, 057607 (2015).

[88] J. A. E. Wasey, A. Safonov, I. D. W. Samuel, and W. L. Barnes, Effects of dipole orientation and birefringence on the optical emission from thin films, Opt. Commun. 183, 109 (2000).

[89] L. Penninck, P. De Visschere, J. Beeckman, and K. Neyts, Dipole radiation within one-dimensional anisotropic microcavities: A simulation method, Opt. Express 19, 18558 (2011).

[90] J. S. Lee, J.-H. Ko, J. Park, and J. W. Lee, Simulation study on the effect of the emitter orientation and photonic crystals on the outcoupling efficiency of organic lightemitting diodes, J. Opt. Soc. Korea 18, 732 (2014).

[91] M. K. Callens, D. Yokoyama, and K. Neyts, Anisotropic materials in OLEDs for high outcoupling efficiency, Opt. Express 23, 21128 (2015).

[92] D. Yokoyama, A. Sakaguchi, M. Suzuki, and C. Adachi, Horizontal molecular orientation in vacuum-deposited organic amorphous films of hole and electron transport materials, Appl. Phys. Lett. 93, 173302 (2008).

[93] D. Yokoyama, A. Sakaguchi, M. Suzuki, and C. Adachi, Enhancement of electron transport by horizontal molecular orientation of oxadiazole planar molecules in organic amorphous films, Appl. Phys. Lett. 95, 243303 (2009).

[94] D. Yokoyama, Y. Setoguchi, A. Sakaguchi, M. Suzuki, and C. Adachi, Orientation control of linear-shaped molecules in vacuum-deposited organic amorphous films and its effect on carrier mobilities, Adv. Funct. Mater. 20, 386 (2010).

[95] Y. Noguchi, Y. Miyazaki, Y. Tanaka, N. Sato, Y. Nakayama, T. D. Schmidt, W. Brütting, and H. Ishii, Charge accumulation at organic semiconductor interfaces due to a permanent dipole moment and its orientational order in bilayer devices, J. Appl. Phys. 111, 114508 (2012).

[96] T. Matsushima, K. Shiomura, S. Naka, and H. Murata, Optical, morphological, structural, electrical, molecular orientation, and electroluminescence characteristics of organic semiconductor films prepared at various deposition rates, Thin Solid Films 520, 2283 (2012).

[97] T. Matsushima and H. Murata, Enhancement of hole injection and electroluminescence characteristics by a rubbing-induced lying orientation of alpha-sexithiophene, J. Appl. Phys. 112, 024503 (2012).

[98] J. Y. Kim, D. Yokoyama, and C. Adachi, Horizontal orientation of disk-like hole transport molecules and their application for organic light-emitting diodes requiring a lower driving voltage, J. Phys. Chem. C 116, 8699 (2012).

[99] Y. Noguchi, H. Lim, T. Isoshima, E. Ito, M. Hara, W. Won Chin, J. Wook Han, H. Kinjo, Y. Ozawa, Y. Nakayama, and $\mathrm{H}$. Ishii, Influence of the direction of spontaneous orientation polarization on the charge injection properties of organic light-emitting diodes, Appl. Phys. Lett. 102, 203306 (2013).

[100] T. Komino, H. Nomura, M. Yahiro, and C. Adachi, Reorganization of the molecular orientation at the organic/substrate interface in spirofluorene thin films, Chem. Phys. Lett. 563, 70 (2013).

[101] Y. Watanabe, H. Sasabe, D. Yokoyama, T. Beppu, H. Katagiri, Y.-J. Pu, and J. Kido, Simultaneous manipulation of intramolecular and intermolecular hydrogen bonds in $n$-type organic semiconductor layers: Realization of horizontal orientation in OLEDs, Adv. Opt. Mater. 3, 769 (2015).

[102] Y. Watanabe, H. Sasabe, D. Yokoyama, T. Beppu, H. Katagiri, and J. Kido, Synthesis, properties, and OLED characteristics of 2,2[prime or minute]-bipyridine-based electron-transport materials: The synergistic effect of molecular shape anisotropy and a weak hydrogen-bonding network on molecular orientation, J. Mater. Chem. C 4, 3699 (2016).

[103] L. Jäger, T. D. Schmidt, and W. Brütting, Manipulation and control of the interfacial polarization in organic lightemitting diodes by dipolar doping, AIP Adv. 6, 095220 (2016).

[104] C. H. Cheng, J. Wang, G. T. Du, S. H. Shi, Z. J. Du, Z. Q. Fan, J. M. Bian, and M. S. Wang, Organic solar cells with remarkable enhanced efficiency by using a $\mathrm{CuI}$ buffer to control the molecular orientation and modify the anode, Appl. Phys. Lett. 97, 083305 (2010).

[105] K. Hinrichs, M. Levichkova, D. Wynands, K. Walzer, K. J. Eichhorn, P. Bäuerle, K. Leo, and M. Riede, Morphology and molecular orientation of ethyl-substituted dicyanovinyl-sexithiophene films for photovoltaic applications, Thin Solid Films 525, 97 (2012).

[106] B. P. Rand, D. Cheyns, K. Vasseur, N. C. Giebink, S. Mothy, Y. Yi, V. Coropceanu, D. Beljonne, J. Cornil, J.-L. Brédas, and J. Genoe, The impact of molecular orientation on the photovoltaic properties of a phthalocyanine/fullerene heterojunction, Adv. Funct. Mater. 22, 2987 (2012).

[107] D. Yokoyama, Z. Q. Wang, Y.-J. Pu, K. Kobayashi, J. Kido, and Z. Hong, High-efficiency simple planar heterojunction organic thin-film photovoltaics with horizontally oriented amorphous donors, Sol. Energy Mater. Sol. Cells 98, 472 (2012).

[108] C.-T. Chou, W.-L. Tang, Y. Tai, C.-H. Lin, C.-H. J. Liu, L.-C. Chen, and K.-H. Chen, Effect of substrate temperature on orientation of subphthalocyanine molecule in organic photovoltaic cells, Thin Solid Films 520, 2289 (2012).

[109] W. Ma, J. R. Tumbleston, M. Wang, E. Gann, F. Huang, and H. Ade, Domain purity, miscibility, and molecular orientation at donor/acceptor interfaces in high performance organic solar cells: Paths to further improvement, Adv. Energy Mater. 3, 864 (2013).

[110] J. R. Tumbleston, B. A. Collins, L. Yang, A. C. Stuart, E. Gann, W. Ma, W. You, and H. Ade, The influence of molecular orientation on organic bulk heterojunction solar cells, Nat. Photonics 8, 385 (2014).

[111] U. Hörmann, C. Lorch, A. Hinderhofer, A. Gerlach, M. Gruber, J. Kraus, B. Sykora, S. Grob, T. Linderl, A. Wilke, 
A. Opitz, R. Hansson, A. S. Anselmo, Y. Ozawa, Y. Nakayama, H. Ishii, N. Koch, E. Moons, F. Schreiber, and W. Brütting, $V_{\mathrm{OC}}$ from a morphology point of view: The influence of molecular orientation on the open circuit voltage of organic planar heterojunction solar cells, J. Phys. Chem. C 118, 26462 (2014).

[112] M. Gruber, M. Mayr, T. Lampe, B.-C. Gallheber, B. J. Scholz, and W. Brütting, Influence of molecular orientation on the coupling of surface plasmons to excitons in semitransparent inverted organic solar cells, Appl. Phys. Lett. 106, 083303 (2015).

[113] Y.-Q. Zheng, J. Zhang, F. Yang, T. Komino, B. Wei, J. Zhang, Z. Wang, W. Pu, C. Yang, and C. Adachi, Influence of deposition substrate temperature on the morphology and molecular orientation of chloroaluminum phthalocyanine films as well the performance of organic photovoltaic cells, Nanotechnology 26, 405202 (2015).

[114] V. Vohra, K. Kawashima, T. Kakara, T. Koganezawa, I. Osaka, K. Takimiya, and H. Murata, Efficient inverted polymer solar cells employing favourable molecular orientation, Nat. Photonics 9, 403 (2015).

[115] S. Lee, H. Shin, and J.-J. Kim, High-efficiency orange and tandem white organic light-emitting diodes using phosphorescent dyes with horizontally oriented emitting dipoles, Adv. Mater. 26, 5864 (2014).

[116] T. D. Schmidt, D. S. Setz, M. Flämmich, J. Frischeisen, D. Michaelis, C. Mayr, A. F. Rausch, T. Wehlus, B. J. Scholz, T. C. G. Reusch, N. Danz, and W. Brütting, Comprehensive efficiency analysis of organic light-emitting diodes featuring emitter orientation and triplet-to-singlet upconversion, Appl. Phys. Lett. 103, 093303 (2013).

[117] C. Mayr, S. Y. Lee, T. D. Schmidt, T. Yasuda, C. Adachi, and W. Brütting, Efficiency enhancement of organic lightemitting diodes incorporating a highly oriented thermally activated delayed fluorescence emitter, Adv. Funct. Mater. 24, 5232 (2014).

[118] F. Wang and T. Ziegler, Time-dependent density functional theory based on a noncollinear formulation of the exchange-correlation potential, J. Chem. Phys. 121, 12191 (2004).

[119] F. Wang and T. Ziegler, A simplified relativistic timedependent density-functional theory formalism for the calculations of excitation energies including spin-orbit coupling effect, J. Chem. Phys. 123, 154102 (2005).

[120] F. Wang, T. Ziegler, E. van Lenthe, S. van Gisbergen, and E. J. Baerends, The calculation of excitation energies based on the relativistic two-component zeroth-order regular approximation and time-dependent density-functional with full use of symmetry, J. Chem. Phys. 122, 204103 (2005).

[121] I. Tunell, Z. Rinkevicius, O. Vahtras, P. Saek, T. Helgaker, and H. Ágren, Density functional theory of nonlinear triplet response properties with applications to phosphorescence, J. Chem. Phys. 119, 11024 (2003).

[122] J. Gao, W. Liu, B. Song, and C. Liu, Time-dependent four-component relativistic density functional theory for excitation energies, J. Chem. Phys. 121, 6658 (2004).

[123] J. Gao, W. Zou, W. Liu, Y. Xiao, D. Peng, B. Song, and C. Liu, Time-dependent four-component relativistic densityfunctional theory for excitation energies. ii. The exchangecorrelation kernel, J. Chem. Phys. 123, 054102 (2005).
[124] Z. Li, B. Suo, Y. Zhang, Y. Xiao, and W. Liu, Combining spin-adapted open-shell TD-DFT with spin-orbit coupling, Mol. Phys. 111, 3741 (2013).

[125] S. Perumal, B. Minaev, and H. Ágren, Spin-spin and spinorbit interactions in nanographene fragments: A quantum chemistry approach, J. Chem. Phys. 136, 104702 (2012).

[126] E. Van Lenthe, E. J. Baerends, and J. G. Snijders, Relativistic regular two-component Hamiltonians, J. Chem. Phys. 99, 4597 (1993).

[127] E. Vanlenthe, E. J. Baerends, and J. G. Snijders, Relativistic total-energy using regular approximations, J. Chem. Phys. 101, 9783 (1994).

[128] E. vanLenthe, J. G. Snijders, and E. J. Baerends, The zeroorder regular approximation for relativistic effects: The effect of spin-orbit coupling in closed shell molecules, J. Chem. Phys. 105, 6505 (1996).

[129] W. Liu and W. Kutzelnigg, Quasirelativistic theory. II. Theory at matrix level, J. Chem. Phys. 126, 114107 (2007).

[130] W. Liu and D. Peng, Exact two-component Hamiltonians revisited, J. Chem. Phys. 131, 031104 (2009).

[131] W. Kutzelnigg and W. Liu, Quasirelativistic theory equivalent to fully relativistic theory, J. Chem. Phys. 123, 241102 (2005).

[132] K. Mori, T. P. M. Goumans, E. van Lenthe, and F. Wang, Predicting phosphorescent lifetimes and zero-field splitting of organometallic complexes with time-dependent density functional theory including spin-orbit coupling, Phys. Chem. Chem. Phys. 16, 14523 (2014).

[133] J. M. Younker and K. D. Dobbs, Correlating experimental photophysical properties of iridium(III) complexes to spin orbit coupled TDDFT predictions, J. Phys. Chem. C 117, 25714 (2013).

[134] A. R. G. Smith, P. L. Burn, and B. J. Powell, Spin-orbit coupling in phosphorescent iridium(III) complexes, ChemPhysChem 12, 2429 (2011).

[135] H. B. Li, S. X. Wu, Y. Liao, Z. M. Su, Y. H. Kan, and X. L. Tang, Density functional theory studies on structures and absorption spectra of $\mathrm{Au}(\mathrm{tpy}) \mathrm{Cl}^{2+}$ and its derivatives: Role of basis set, functional, solvent effect, and spin orbit effect, Int. J. Quantum Chem. 112, 1642 (2012).

[136] E. Ronca, F. De Angelis, and S. Fantacci, Time-dependent density functional theory modeling of spin-orbit coupling in ruthenium and osmium solar cell sensitizers, J. Phys. Chem. C 118, 17067 (2014).

[137] K. H. Kim, E. S. Ahn, J. S. Huh, Y. H. Kim, and J. J. Kim, Design of heteroleptic Ir complexes with horizontal emitting dipoles for highly efficient organic light-emitting diodes with an external quantum efficiency of $38 \%$, Chem. Mater. 28, 7505 (2016).

[138] Materials ScIEnCE Suite 2016-4,Schrödinger, LLC, 2016.

[139] Highly Efficient OLEDs with Phosphorescent Materials, edited by H. Yersin (Wiley-VCH, New York, 2007).

[140] G. E. Jellison, Data analysis for spectroscopic ellipsometry, Thin Solid Films 234, 416 (1993).

[141] H.-W. Lin, C.-L. Lin, H.-H. Chang, Y.-T. Lin, C.-C. Wu, Y.-M. Chen, R.-T. Chen, Y.-Y. Chien, and K.-T. Wong, Anisotropic optical properties and molecular orientation in vacuum-deposited ter(9,9-diarylfluorene)s thin films using spectroscopic ellipsometry, J. Appl. Phys. 95, 881 (2004). 
[142] M. C. Gather and D. D. C. Bradley, An improved optical method for determining the order parameter in thin oriented molecular films and demonstration of a highly axial dipole moment for the lowest energy $\pi-\pi *$ optical transition in poly(9,9-dioctylfluorene-co-bithiophene), Adv. Funct. Mater. 17, 479 (2007).

[143] D. Yokoyama and C. Adachi, In situ real-time spectroscopic ellipsometry measurement for the investigation of molecular orientation in organic amorphous multilayer structures, J. Appl. Phys. 107, 123512 (2010).

[144] D. Yokoyama, Molecular orientation in small-molecule organic light-emitting diodes, J. Mater. Chem. 21, 19187 (2011).

[145] C. Schünemann, D. Wynands, K.-J. Eichhorn, M. Stamm, K. Leo, and M. Riede, Evaluation and control of the orientation of small molecules for strongly absorbing organic thin films, J. Phys. Chem. C 117, 11600 (2013).

[146] I. M. Ward, Structure and Properties of Oriented Polymers, 3rd ed. (Springer Science \& Business Media, New York, 2012).

[147] J. Frischeisen, D. Yokoyama, C. Adachi, and W. Brütting, Determination of molecular dipole orientation in doped fluorescent organic thin films by photoluminescence measurements, Appl. Phys. Lett. 96, 073302 (2010).

[148] M. Flämmich, M. C. Gather, N. Danz, D. Michaelis, A. H. Bräuer, K. Meerholz, and A. Tünnermann, Orientation of emissive dipoles in OLEDs: Quantitative in situ analysis, Org. Electron. 11, 1039 (2010).

[149] M. C. Gather, M. Flämmich, N. Danz, D. Michaelis, and K. Meerholz, Measuring the profile of the emission zone in polymeric organic light-emitting diodes, Appl. Phys. Lett. 94, 263301 (2009).

[150] S. L. M. van Mensfoort, M. Carvelli, M. Megens, D. Wehenkel, M. Bartyzel, H. Greiner, R. A. J. Janssen, and R. Coehoorn, Measuring the light emission profile in organic light-emitting diodes with nanometer spatial resolution, Nat. Photonics 4, 329 (2010).

[151] M. Flämmich, D. Michaelis, and N. Danz, In situ measurement of spectrum, emission zone, and dipole emitter orientation in OLEDs, Proc. SPIE Int. Soc. Opt. Eng. 7954, 795410 (2011).

[152] N. Danz, M. Flämmich, D. S. Setz, B. C. Krummacher, D. Michaelis, and T. Dobbertin, Detection of sub-10 nm emission profile features in organic light-emitting diodes using destructive interference, Opt. Lett. 37, 4134 (2012).

[153] N. Danz, R. MacCiarnain, D. Michaelis, T. Wehlus, A. F. Rausch, C. A. Wächter, and T.C.G. Reusch, OLED emission zone measurement with high accuracy, Proc. SPIE Int. Soc. Opt. Eng. 8829, 882923 (2013).

[154] S. H. Garrett, J. A. E. Wasey, and W. L. Barnes, Determining the orientation of the emissive dipole moment associated with dye molecules in microcavity structures, J. Mod. Opt. 51, 2287 (2004).

[155] G. W. Ford and W. H. Weber, Electromagnetic interactions of molecules with metal surfaces, Phys. Rep. 113, 195 (1984).

[156] L. Penninck, F. Steinbacher, R. Krause, and K. Neyts, Determining emissive dipole orientation in organic light emitting devices by decay time measurement, Org. Electron. 13, 3079 (2012).
[157] T. D. Schmidt, L. J. Reichardt, A. F. Rausch, S. Wehrmeister, B. J. Scholz, C. Mayr, T. Wehlus, R. M. Ciarnain, N. Danz, T.C. G. Reusch, and W. Brütting, Extracting the emitter orientation in organic light-emitting diodes from external quantum efficiency measurements, Appl. Phys. Lett. 105, 043302 (2014).

[158] Y. Sakai, M. Shibata, and D. Yokoyama, Simple modelfree estimation of orientation order parameters of vacuumdeposited and spin-coated amorphous films used in organic light-emitting diodes, Appl. Phys. Express 8, 096601 (2015).

[159] H.-W. Lin, C.-L. Lin, C.-C. Wu, T.-C. Chao, and K.-T. Wong, Influences of molecular orientations on stimulated emission characteristics of oligofluorene films, Org. Electron. 8, 189 (2007).

[160] S. S. Dalal, D. M. Walters, I. Lyubimov, J. J. de Pablo, and M. D. Ediger, Tunable molecular orientation and elevated thermal stability of vapor-deposited organic semiconductors, Proc. Natl. Acad. Sci. U.S.A. 112, 4227 (2015).

[161] D. Yokoyama, A. Sakaguchi, M. Suzuki, and C. Adachi, Horizontal orientation of linear-shaped organic molecules having bulky substituents in neat and doped vacuumdeposited amorphous films, Org. Electron. 10, 127 (2009).

[162] D. Marcuse, in Theory of Dielectric Optical Waveguides, 2nd ed., edited by P. Liao (Academic Press, New York, 1991).

[163] A. K. Sheridan, G. A. Turnbull, A. N. Safonov, and I. D. W. Samuel, Tuneability of amplified spontaneous emission through control of the waveguide-mode structure in conjugated polymer films, Phys. Rev. B 62, R11929 (2000).

[164] X. Peng, L. Liu, J. Wu, Y. Li, Z. Hou, L. Xu, W. Wang, F. $\mathrm{Li}$, and M. Ye, Wide-range amplified spontaneous emission wavelength tuning in a solid-state dye waveguide, Opt. Lett. 25, 314 (2000).

[165] T. Kawase, D. J. Pinner, R. H. Friend, and T. Shimoda, Grazing emitted light from films of derivative polymer of polyfluorene, Synth. Met. 111-112, 583 (2000).

[166] M. Pauchard, J. Swensen, D. Moses, A. J. Heeger, E. Perzon, and M.R. Andersson, Light amplification in polymer field effect transistor structures, J. Appl. Phys. 94, 3543 (2003).

[167] K.-H. Yim, R. Friend, and J.-S. Kim, Anisotropic optical properties in electroluminescent conjugated polymers based on grazing angle photoluminescence measurements, J. Chem. Phys. 124, 184706 (2006).

[168] F. Li, O. Solomesch, P. R. Mackie, D. Cupertino, and N. Tessler, Low gain threshold of the cavity mode close to the cutoff wavelength in a three-slab asymmetric conjugated polymer-based waveguide structure, J. Appl. Phys. 99, 013101 (2006).

[169] D. Y. Kondakov, Characterization of triplet-triplet annihilation in organic light-emitting diodes based on anthracene derivatives, J. Appl. Phys. 102, 114504 (2007).

[170] S.-K. Kim, B. Yang, Y. Ma, J.-H. Lee, and J.-W. Park, Exceedingly efficient deep-blue electroluminescence from new anthracenes obtained using rational molecular design, J. Mater. Chem. 18, 3376 (2008).

[171] K. Okumoto, H. Kanno, Y. Hamaa, H. Takahashi, and K. Shibata, Green fluorescent organic light-emitting device 
with external quantum efficiency of nearly 10\%, Appl. Phys. Lett. 89, 063504 (2006).

[172] M. Tian, J. Luo, and X. Liu, Highly efficient organic lightemitting devices beyond theoretical prediction under high current density, Opt. Express 17, 21370 (2009).

[173] K.-H. Kim, J. Y. Baek, C. W. Cheon, C.-K. Moon, B. Sim, M. Y. Choi, J.-J. Kim, and Yun-Hi Kim, Highly efficient non-doped deep blue fluorescent emitters with horizontal emitting dipoles using interconnecting units between chromophores, Chem. Commun. (Cambridge) 52, 10956 (2016).

[174] A. Endo, M. Ogasawara, A. Takahashi, D. Yokoyama, Y. Kato, and C. Adachi, Thermally activated delayed fluorescence from $\mathrm{Sn}^{4+}$ porphyrin complexes and their application to organic light emitting diodes a novel mechanism for electroluminescence, Adv. Mater. 21, 4802 (2009).

[175] R. Czerwieniec, J. Yu, and H. Yersin, Blue-light emission of $\mathrm{Cu}(\mathrm{I})$ complexes and singlet harvesting, Inorg. Chem. 50, 8293 (2011).

[176] A. Endo, K. Sato, K. Yoshimura, T. Kai, A. Kawada, H. Miyazaki, and C. Adachi, Efficient up-conversion of triplet excitons into a singlet state and its application for organic light emitting diodes, Appl. Phys. Lett. 98, 083302 (2011).

[177] S. Youn Lee, T. Yasuda, H. Nomura, and C. Adachi, Highefficiency organic light-emitting diodes utilizing thermally activated delayed fluorescence from triazine-based donor acceptor hybrid molecules, Appl. Phys. Lett. 101, 093306 (2012).

[178] T. Komino, H. Tanaka, and C. Adachi, Selectively controlled orientational order in linear-shaped thermally activated delayed fluorescent dopants, Chem. Mater. 26, 3665 (2014).

[179] M. Taneda, K. Shizu, H. Tanaka, and C. Adachi, High efficiency thermally activated delayed fluorescence based on 1,3,5-tris(4-(diphenylamino)phenyl)-2,4,6-tricyanobenzene, Chem. Commun. (Cambridge) 51, 5028 (2015).

[180] H. Kaji, H. Suzuki, T. Fukushima, K. Shizu, K. Suzuki, S. Kubo, T. Komino, H. Oiwa, F. Suzuki, A. Wakamiya, Y. Murata, and C. Adachi, Purely organic electroluminescent material realizing $100 \%$ conversion from electricity to light, Nat. Commun. 6, 8476 (2015).

[181] W. Zhang, J. Jin, Z. Huang, S. Zhuang, and L. Wang, A new way towards high-efficiency thermally activated delayed fluorescence devices via external heavy-atom effect, Sci. Rep. 6, 30178 (2016).

[182] S. Y. Lee, C. Adachi, and T. Yasuda, High-efficiency blue organic light-emitting diodes based on thermally activated delayed fluorescence from phenoxaphosphine and phenoxathiin derivatives, Adv. Mater. 28, 4626 (2016).

[183] G. H. Lee and Y.S. Kim, High-efficiency diphenylsulfon derivative-based organic light-emitting diode exhibiting thermally-activated delayed fluorescence, J. Korean Phys. Soc. 69, 398 (2016).

[184] T. Lin, T. Zhang, Q. Song, F. Jin, Z. Liu, Z. Su, Y. Luo, B. Chu, C. S. Lee, and W. Li, Thermally activated delayedfluorescence organic light-emitting diodes based on exciplex emitter with high efficiency and low roll-off, Org. Electron. 38, 69 (2016).

[185] T. Komino, Y. Sagara, H. Tanaka, Y. Oki, N. Nakamura, H. Fujimoto, and C. Adachi, Electroluminescence from completely horizontally oriented dye molecules, Appl. Phys. Lett. 108, 241106 (2016).

[186] C. S. Oh, C.-K. Moon, J. M. Choi, J.-S. Huh, J.-J. Kim, and J. Y. Lee, Relationship between molecular structure and dipole orientation of thermally activated delayed fluorescent emitters, Org. Electron. 42, 337 (2017).

[187] S. S. Dalal, Z. Fakhraai, and M. D. Ediger, High-throughput ellipsometric characterization of vapor-deposited indomethacin glasses, J. Phys. Chem. B 117, 15415 (2013).

[188] S. F. Swallen, K. L. Kearns, M. K. Mapes, Y. S. Kim, R. McMahon, M. D. Ediger, T. Wu, L. Yu, and S. Satija, Organic glasses with exceptional thermodynamic and kinetic stability, Science 315, 353 (2007).

[189] E. Leon-Gutierrez, G. Garcia, A. F. Lopeandia, M. T. Clavaguera-Mora, and J. Rodriguez-Viejo, Size effects and extraordinary stability of ultrathin vapor deposited glassy films of toluene, J. Phys. Chem. Lett. 1, 341 (2010).

[190] E. Leon-Gutierrez, A. Sepulveda, G. Garcia, M. T. Clavaguera-Mora, and J. Rodriguez-Viejo, Stability of thin film glasses of toluene and ethylbenzene formed by vapor deposition: An in situ nanocalorimetric study, Phys. Chem. Chem. Phys. 12, 14693 (2010).

[191] M. Ahrenberg, Y. Z. Chua, K. R. Whitaker, H. Huth, M. D. Ediger, and C. Schick, In situ investigation of vapordeposited glasses of toluene and ethylbenzene via alternating current chip-nanocalorimetry, J. Chem. Phys. 138, 024501 (2013).

[192] S. S. Dalal and M. D. Ediger, Molecular orientation in stable glasses of indomethacin, J. Phys. Chem. Lett. 3, 1229 (2012).

[193] J. Jiang, D. M. Walters, D. Zhou, and M. D. Ediger, Substrate temperature controls molecular orientation in two-component vapor-deposited glasses, Soft Matter 12, 3265 (2016).

[194] S. Leonard and P. Harrowell, Macroscopic facilitation of glassy relaxation kinetics: Ultrastable glass films with frontlike thermal response, J. Chem. Phys.. 133, 244502 (2010).

[195] T. Komino, H. Nomura, M. Yahiro, and C. Adachi, Realtime measurement of molecular orientational randomization dynamics during annealing treatments by in-situ ellipsometry, J. Phys. Chem. C 116, 11584 (2012).

[196] L. Zhu, C. W. Brian, S. F. Swallen, P. T. Straus, M. D. Ediger, and L. Yu, Surface Self-Diffusion of an Organic Glass, Phys. Rev. Lett. 106, 256103 (2011).

[197] Caleb W. Brian and Lian Yu, Surface self-diffusion of organic glasses, J. Phys. Chem. A 117, 13303 (2013).

[198] I. Lyubimov, M. D. Ediger, and J. J. de Pablo, Model vapor-deposited glasses: Growth front and composition effects, J. Chem. Phys. 139, 144505 (2013).

[199] Y. Chai, T. Salez, J. D. McGraw, M. Benzaquen, K. Dalnoki-Veress, E. Raphaël, and J. A. Forrest, A direct quantitative measure of surface mobility in a glassy polymer, Science 343, 994 (2014).

[200] C. Mayr and W. Brütting, Control of molecular dye orientation in organic luminescent films by the glass transition temperature of the host material, Chem. Mater. 27, 2759 (2015).

[201] Y. Sagara, K. Shizu, H. Tanaka, H. Miyazaki, K. Goushi, H. Kaji, and C. Adachi, Highly efficient thermally activated 
delayed fluorescence emitters with a small singlet-triplet energy gap and large oscillator strength, Chem. Lett. 44, 360 (2015).

[202] K. A. King, P. J. Spellane, and Richard J. Watts, Excitedstate properties of a triply ortho-metalated iridium(III) complex, J. Am. Chem. Soc. 107, 1431 (1985).

[203] B. Schmid, F. O. Garces, and R. J. Watts, Synthesis and characterizations of cyclometalated iridium(III) solvento complexes, Inorg. Chem. 33, 9 (1994).

[204] M. G. Colombo, T. C. Brunold, T. Riedener, H. U. Guedel, M. Fortsch, and H.-B. Buergi, Facial tris-cyclometalated rhodium(3+) and iridium(3+) complexes: Their synthesis, structure, and optical spectroscopic properties, Inorg. Chem. 33, 545 (1994).

[205] S. Lamansky, P. Djurovich, D. Murphy, F. Abdel-Razzaq, R. Kwong, I. Tsyba, M. Bortz, B. Mui, R. Bau, and M. E. Thompson, Synthesis and characterization of phosphorescent cyclometalated iridium complexes, Inorg. Chem. 40, 1704 (2001).

[206] S. Lamansky, P. Djurovich, D. Murphy, F. Abdel-Razzaq, H.-E. Lee, C. Adachi, P. E. Burrows, S. R. Forrest, and M. E. Thompson, Highly phosphorescent bis-cyclometalated iridium complexes: Synthesis, photophysical characterization, and use in organic light emitting diodes, J. Am. Chem. Soc. 123, 4304 (2001).

[207] W. J. Finkenzeller and H. Yersin, Emission of $\operatorname{Ir}($ ppy)3. temperature dependence, decay dynamics, and magnetic field properties, Chem. Phys. Lett. 377, 299 (2003).

[208] F. Steiner, S. Bange, J. Vogelsang, and J. M. Lupton, Spontaneous fluctuations of transition dipole moment orientation in OLED triplet emitters, J. Phys. Chem. Lett. 6, 999 (2015).

[209] A. Graf, P. Liehm, C. Murawski, S. Hofmann, K. Leo, and M.C. Gather, Correlating the transition dipole moment orientation of phosphorescent emitter molecules in OLEDs with basic material properties, J. Mater. Chem. C 2, 10298 (2014).

[210] T. Lampe, T. D. Schmidt, M. J. Jurow, P. I. Djurovich, M. E. Thompson, and W. Brütting, Dependence of phosphorescent emitter orientation on deposition technique in doped organic films, Chem. Mater. 28, 712 (2016).

[211] P. Liehm, C. Murawski, M. Furno, B. Lüssem, K. Leo, and M. C. Gather, Comparing the emissive dipole orientation of two similar phosphorescent green emitter molecules in highly efficient organic light-emitting diodes, Appl. Phys. Lett. 101, 253304 (2012).

[212] C. Fuchs, P.-A. Will, M. Wieczorek, M. C. Gather, S. Hofmann, S. Reineke, K. Leo, and R. Scholz, Enhanced light emission from top-emitting organic light-emitting diodes by optimizing surface plasmon polariton losses, Phys. Rev. B 92, 245306 (2015).

[213] J.-B. Kim, J.-H. Lee, C.-K. Moon, K.-H. Kim, and J.-J. Kim, Highly efficient inverted top emitting organic light emitting diodes using a horizontally oriented green phosphorescent emitter, Org. Electron. 15, 2715 (2014).

[214] C.-K. Moon, S.-Y. Kim, J.-H. Lee, and J.-J. Kim, Luminescence from oriented emitting dipoles in a birefringent medium, Opt. Express 23, A279 (2015).

[215] L.-S. Cui, Y. Liu, X.-Y. Liu, Z.-Q. Jiang, and L.-S. Liao, Design and synthesis of pyrimidine-based iridium(III) complexes with horizontal orientation for orange and white phosphorescent OLEDs, ACS Appl. Mater. Interfaces 7, 11007 (2015).

[216] J.-H. Lee, G. Sarada, C.-K. Moon, Wo. Cho, K.-H. Kim, Y. G. Park, J. Y. Lee, S.-H. Jin, and J.-J. Kim, Finely tuned blue iridium complexes with varying horizontal emission dipole ratios and quantum yields for phosphorescent organic light-emitting diodes, Adv. Opt. Mater. 3, 211 (2015).

[217] M. J. Jurow, C. Mayr, T. D. Schmidt, T. Lampe, P. I. Djurovich, W. Brütting, and M. E. Thompson, Understanding and predicting the orientation of heteroleptic phosphors in organic light-emitting materials, Nat. Mater. 15, 85 (2016).

[218] C.-K. Moon, K.-H. Kim, J. W. Lee, and J.-J. Kim, Influence of host molecules on emitting dipole orientation of phosphorescent iridium complexes, Chem. Mater. 27, 2767 (2015).

[219] K.-H. Kim, S. Lee, C.-K. Moon, S.-Y. Kim, Y.-S. Park, J.-H. Lee, J. Woo Lee, J. Huh, Y. You, and J.-J. Kim, Phosphorescent dye-based supramolecules for highefficiency organic light-emitting diodes, Nat. Commun. 5, 4769 (2014).

[220] S.-Y. Kim, W.-I. Jeong, C. Mayr, Y.-S. Park, K.-H. Kim, J.-H. Lee, C.-K. Moon, W. Brütting, and J.-J. Kim, Organic light-emitting diodes with $30 \%$ external quantum efficiency based on a horizontally oriented emitter, Adv. Funct. Mater. 23, 3896 (2013).

[221] K.-H. Kim, C.-K. Moon, J.-H. Lee, S.-Y. Kim, and J.-J. Kim, Highly efficient organic light-emitting diodes with phosphorescent emitters having high quantum yield and horizontal orientation of transition dipole moments, Adv. Mater. 26, 3844 (2014).

[222] H. Shin, S. Lee, K.-H. Kim, C.-K. Moon, S.-J. Yoo, J.-H. Lee, and J.-J. Kim, Blue phosphorescent organic lightemitting diodes using an exciplex forming co-host with the external quantum efficiency of theoretical limit, Adv. Mater. 26, 4730 (2014).

[223] K.-H. Kim, J.-Y. Ma, C.-K. Moon, J.-H. Lee, J. Y. Baek, Y.-H. Kim, and J.-J. Kim, Controlling emitting dipole orientation with methyl substituents on main ligand of iridium complexes for highly efficient phosphorescent organic light-emitting diodes, Adv. Opt. Mater. 3, 1191 (2015).

[224] H. Shin, J.-H. Lee, C.-K. Moon, J.-S. Huh, B. Sim, and J.-J. Kim, Sky-blue phosphorescent OLESD with $34.1 \%$ external quantum efficiency using a low refractive index electron transporting layer, Adv. Mater. 28, 4920 (2016).

[225] K.-H. Kim, E. S. Ahn, J.-S. Huh, Y.-H. Kim, and J.-J. Kim, Design of heteroleptic Ir complexes with horizontal emitting dipoles for highly efficient organic light-emitting diodes with an external quantum efficiency of $38 \%$, Chem. Mater. 28, 7505 (2016).

[226] M. G. Helander, Z. B. Wang, J. Qiu, M. T. Greiner, D. P. Puzzo, Z. W. Liu, and Z. H. Lu, Chlorinated indium tin oxide electrodes with high work function for organic device compatibility, Science 332, 944 (2011).

[227] F. W. M. Vanhelmont, G. F. Strouse, H. U. Gudel, A. C. Stuckl, and H. W. Schmalle, Synthesis, crystal structure, high-resolution optical spectroscopy, and extended Huckel 
calculations on cyclometalated $\operatorname{Re}(\mathrm{CO})(4)(\mathrm{ppy})$ (ppy = 2-phenylpyridine), J. Phys. Chem. A 101, 2946 (1997).

[228] T. Lampe, F. F. Navarro, J. Facendola, M. J. Jurow, T. D. Schmidt, P. I. Djurovich, M. E. Thompson, and W. Brütting, Orientation of phosphorescent dopants in organic vapor phase deposited films (to be published).

[229] K.-H. Kim, J.-L. Liao, S. W. Lee, B. Sim, C.-K. Moon, G.-H. Lee, H. J. Kim, Y. Chi, and J.-J. Kim, Crystal organic light-emitting diodes with perfectly oriented non-doped Pt-based emitting layer, Adv. Mater. 28, 2526 (2016).

[230] M. Taneda, T. Yasuda, and C. Adachi, Horizontal orientation of a linear-shaped platinum(II) complex in organic light-emitting diodes with a high light out-coupling efficiency, Appl. Phys. Express 4, 071602 (2011).

[231] C. Mayr, M. Taneda, C. Adachi, and W. Brütting, Different orientation of the transition dipole moments of two similar $\mathrm{Pt}$ (II) complexes and their potential for high efficiency organic light-emitting diodes, Org. Electron. 15, 3031 (2014).

[232] J.-S. Huh, K.-H. Kim, C.-K. Moon, and J.-J. Kim, Dependence of $\mathrm{Pt}(\mathrm{II})$ based phosphorescent emitter orientation on host molecule orientation in doped organic thin films, Org. Electron. 45, 279 (2017). 